OPEN ACCESS

Edited by:

Luciano Pasqualoto Canellas,

State University of the North

Fluminense Darcy Ribeiro, Brazil

Reviewed by:

Daniel Basilio Zandonadi,

Federal University of Rio de Janeiro, Brazil

Andrés Calderín García,

Universidade Federal Rural do Rio de Janeiro, Brazil

*Correspondence: Hiarhi Monda hiarhi.monda@bhn.us

Specialty section: This article was submitted to Crop and Product Physiology, a section of the journal

Frontiers in Plant Science

Received: 29 January 2021 Accepted: 28 April 2021

Published: 26 May 2021

Citation:

Monda H, McKenna AM, Fountain R and Lamar RT (2021) Bioactivity of Humic Acids Extracted From Shale Ore: Molecular Characterization and Structure-Activity Relationship With Tomato Plant Yield Under Nutritional Stress. Front. Plant Sci. 12:660224. doi: 10.3389/fpls.2021.660224

\section{Bioactivity of Humic Acids Extracted From Shale Ore: Molecular Characterization and Structure-Activity Relationship With Tomato Plant Yield Under Nutritional Stress}

\author{
Hiarhi Monda ${ }^{1 *}$, Amy M. McKenna ${ }^{2}$, Ryan Fountain ${ }^{1}$ and Richard T. Lamar ${ }^{1}$ \\ ${ }^{1}$ Humic R\&D Lab, Bio Huma Netics, Inc., Gillbert, AZ, United States, ${ }^{2}$ National High Magnetic Field Laboratory, Ion Cyclotron \\ Resonance Facility, Tallahassee, FL, United States
}

The increasing demands for biostimulants in the agricultural market over the last years have posed the problem of regulating this product category by requiring the industry to make available the information about efficacy and safety, including the explanation of mode of action and the definition of bioactive constituents. In the present study, we tested the biostimulant proprieties of a sedimentary shale ore-extracted humic acid (HA) on Micro Tom tomato plants under increasing nutritional stress and investigated the correlation with the chemical features of HA by means of ultra-high resolution FT-ICR MS, FT-ATR, and ${ }^{13} \mathrm{C}-\mathrm{NMR}$. Humic acid application proved effective in alleviating the nutritional stress by improving nutrient use efficiency, with results comparable to the control treatment supplied with higher NPK nutrition. Increased yield (up to $+19 \%$ ) and fruit quality (in the range $+10-24 \%$ ), higher ascorbic acid content and a better root growth were the main parameters affected by HA application. Molecular-level characterization identified the possible chemical drivers of bioactivity, and included flavonoids, quinones, and alkaloids among the most represented molecules, some of which exhibiting antioxidant, pro-oxidant, and antimicrobial activity. The redox effect was discussed as a determinant of the delicate homeostasis balance, capable of triggering plant defense response and eventually inducing a protective priming effect on the plants.

Keywords: humic acids, biostimulant activity, nutrient stress, FT-ICR MS of humic substances, reactive oxygen species, redox (bio)geochemistry, antioxidant and prooxidant, quinones and flavonoids

\section{INTRODUCTION}

Humic substances (HS) are the major component of natural organic matter (NOM), a complex mixture of organic compounds naturally occurring in soils, water, and sediments (Stevenson, 1994). The current use of the operationally based definition of HS fractions, although originally applied strictly to the soil, has been applied to a variety of different sources (Weber et al., 2018). Soil, peat, ores, sediments, leonardite, lignite, compost, and plant are just some sources out of a 
possibly longer list, each one performing differently based on its own chemistry. During the last two centuries the knowledge about direct and indirect effects of HS on soil fertility and plant growth has evolved, but the complexity of their constituents and the diversity of each source did not allow the harmonization and standardization of the information accumulated. Conversely, supported by the lack of appropriate technologies and a vague operational definition, ambiguities, and uncertainties about HS origin and chemical structure arised (Kelleher and Simpson, 2006; Kleber and Lehmann, 2019; Olk et al., 2019; Hayes and Swift, 2020). As a consequence, the understanding of their mode of action has been delayed.

However, the biostimulant proprieties of HS have been gradually recognized by the agricultural community that contributed to pushing the market into a rising trend that is expected to increase the global returns at a rate between 9 and 13.4\% by 2025 (Meticulous Market Research, 2019; Khillari, 2020). This fast expansion has led to the introduction of new government regulations requiring the elucidation of the mode of action to legitimize the biostimulant industry. A detailed characterization of the chemical composition becomes therefore critical in order to understand the structure-activity relationship and to finally supply farmers with effective products with claims based on science.

Nonetheless, the reduction of agrochemicals footprint and the adoption of an efficient nutrient management need to be implemented to promote a sustainable food production (Vitousek et al., 2009; Foley et al., 2011; Rouphael and Colla, 2018).

Much information has been accumulated regarding the mechanisms by which plants react to HS application (Nardi et al., 1991; Canellas et al., 2002, 2015; Zandonadi et al., 2010; Zanin et al., 2018; Pizzeghello et al., 2020; Olaetxea et al., 2021), as well as their interaction with the rhizospheric microbiome, ultimately leading to enhanced plant development (Puglisi et al., 2009, 2013; Maji et al., 2017; De Hita et al., 2020). However, when moving from short time lab-scale experiments to greenhouse or field experiments where final productivity is measured, impaired results are often reported. Azcona et al. (2011) found that pepper plants treated with HS from composted sludge did not show an improved nutrient uptake or differences in total fruit yield, despite an overall increased biomass produced. Similarly, Pilanal and Kaplan (2003) in a 2-year greenhouse experiment found that foliar application of HA did not affect nutrient uptake in mature strawberry leaves.

According to Rose et al. (2014) HS seem to be more effective when plants are grown under stress. A growing body of literature is accumulating about abiotic stress relief of HS, but little research is available on plants subjected to nutrient stress. Tavares et al. (2019) found that rice plants grown hydroponically and pre-treated with $\mathrm{HA}$ showed increased net influx of $\mathrm{NO}_{3}^{-}$ after a temporary nitrogen deprivation. The only paper found addressing the nutrient stress under field conditions reported an increased $\mathrm{P}$ uptake and yield along with the improvement of the antioxidant defense system in maize plants treated with leonardite HA under P deficiency (Kaya et al., 2020). The mitigation of stress has been linked to the ability of HS to prevent ROS induced oxidative damage by modulation of redox homeostasis (García et al., 2016a; Roomi et al., 2018). However, the role of HS chemical structure in biostimulation is not well understood and requires more investigations because an unequivocal relationship has not been identified, despite previous studies which demonstrated the importance of chemical composition and source in predicting the bioactivity of HS (Aguiar et al., 2013; Martinez-Balmori et al., 2014; Monda et al., 2018).

Relevant advances during the last decades, in elucidating the chemical nature of HS, have been achieved using several different techniques such as NMR, pyrolysis GC-MS, LC-MS, FTIR, fluorescence spectroscopy, and HP-SEC. However, although assessing the general chemical nature of these materials by being marginally successful, none of these techniques has yielded molecular level information until the breakthrough introduction of ultra-high-resolution techniques. Fourier transform ion cyclotron resonance mass spectrometry in a high magnetic field (FT-ICR MS) has become one of the most important analytical tools for detailed characterization of complex mixtures due to its ultra-high mass resolving effectiveness. To date, extended literature has been produced on the application of FT-ICR MS to NOM and its fractions, mostly in relation to dissolved organic matter (DOM) (Brown and Rice, 2000; Kujawinski, 2002; Stenson et al., 2002; Sleighter and Hatcher, 2007; Remucal et al., 2012; Lv et al., 2016). But, when it comes to the terrestrial soil organic matter (SOM) and its fractions, only a few publications arise (Kramer et al., 2004; Ohno et al., 2010; Piccolo et al., 2010; Ohno and Ohno, 2013; Zherebker et al., 2019), whereas investigations on other sources such as ores or compost are rare. A recent innovative approach has been incorporated in the pipeline of the studies on biologically active metabolites, where molecular formulas obtained by FT-ICR MS were sourced from public online databases with valuable results that helped gathering insights into the chemistry of HS (Fedoros et al., 2018; Orlov et al., 2019; Zhernov et al., 2020).

The objective of the present study was to investigate in detail the chemical features of HA extracted from sedimentary ore with the aim of exploring the potential relationship of chemical function with biostimulant activity, and to evaluate the extent to which the priming effect of HA on tomato plants under nutritional stress was reflected on the yield gains.

\section{MATERIALS AND METHODS}

\section{Ore Humic Acids Extraction and Elemental Composition}

A sedimentary lignite ore (Idaho, USA), ground to pass a $1,000 \mu \mathrm{m}$ sieve, was used as the source of HA (IDHA). Isolation of HA was obtained by alkaline extraction according to International Humic Substances Society (IHSS) procedure (Swift, 1996). Purification step through $\mathrm{HCl} / \mathrm{HF}$ was performed to reduce the mineral ash content (Lamar et al., 2014).

The elemental composition of the purified HA extract was achieved by combustion analysis. Carbon and Nitrogen were determined by catalytic combustion with a Rapid CS Cube 
combustion analyzer and a Rapid MAX N Exceed combustion analyzer both from Elementar Americas, Inc. (Elementar, Ronkonkoma, NY, USA).

\section{ESI FT-ICR Mass Spectrometry}

Extracted samples were analyzed with a custom-built 9.4 T FTICR mass spectrometer at the National High Magnetic Field Laboratory, equipped with a horizontal, $220 \mathrm{~mm}$ bore diameter operated at room temperature, and a modular ICR data station (Predator 32) facilitated instrument control, data acquisition, and data analysis (Blakney et al., 2011; Kaiser et al., 2014). A purified HA sample was first dissolved in $\mathrm{NH}_{4} \mathrm{OH}$ (30\%), followed by double dilution with $\mathrm{MeOH}: \mathrm{H}_{2} \mathrm{O}$ (1:1) to a concentration of $100 \mathrm{mg} \mathrm{L}^{-1}$ (Rostad and Leenheer, 2004). The mass spectrum was acquired in negative ionization mode with an introduction flow rate of $0.5 \mu \mathrm{L} \mathrm{min}^{-1}$, ESI needle voltage of-3,000 V, 100 scan accumulation, and $400 \mathrm{~ms}$ event length. 100 individual transients of 5.8-6.1 s duration collected for crude extracts were averaged, apodized with a Hanning weight function, and zero-filled once prior to fast Fourier transformation. For all mass spectra, the achieved spectral resolving power approached the theoretical limit over the entire mass range, e.g., average resolving power, $\mathrm{m} / \Delta \mathrm{m}_{50 \%}$, in which $\Delta \mathrm{m}_{50 \%}$ is mass spectral peak full width at half-maximum peak height was $\sim 1,000,000$ $1,300,000$ for absorption mode at $\mathrm{m} / \mathrm{z} 500$ for all mass spectra and processed in absorption mode (Beu et al., 2004; Xian et al., 2010, 2012). Peaks with signal magnitude greater than six times the baseline root-mean-square (RMS) noise level were exported to a peak list. The spectrum was internally calibrated by using known methylene homologous series and molecular formula assignments of the resulting mass spectra considering $\mathrm{C}_{\mathrm{c}} \mathrm{H}_{\mathrm{h}} \mathrm{N}_{\mathrm{n}} \mathrm{O}_{\mathrm{o}} \mathrm{S}_{\mathrm{s}}$ chemical species (Savory et al., 2011; McKenna et al., 2019). Mass peaks with $\mathrm{S} / \mathrm{N}>6$ were processed for formula assignment by using the National High Magnetic Field Laboratory, Ion Cyclotron Resonance Facility PetroOrg $\left.{ }^{(}\right)$ software (Corilo, 2018) by setting the following parameters: ${ }^{12} \mathrm{C}_{1-100}{ }^{1} \mathrm{H}_{2-200},{ }^{6} \mathrm{O}_{2-30},{ }^{14} \mathrm{~N}_{0-3},{ }^{32} \mathrm{~S}_{0-3}$ with a mass error threshold set at $\leq 0.5 \mathrm{ppm}$. Formulae having the least $\mathrm{N}$ and $\mathrm{S}$ were assigned first (Kujawinski et al., 2009). Generated formulae were filtered by $\mathrm{O} / \mathrm{C}$ ratio $(\leq 1)$ and $\mathrm{H} / \mathrm{C}$ ratio $(\leq 2)$ according to Koch et al. (2005). The degree of hydrogen and oxygen saturation and molecular heterogeneity were assessed within the assigned formulae and molecular reactivity analyzed based on $\mathrm{H} / \mathrm{C}$ and $\mathrm{O} / \mathrm{C}$ ratios by means of a Van Krevelen diagram (Van Krevelen, 1950) whose molecular compositional space was divided into the typical classes of discrete organic biomolecules found in organic matter according to the following rules: $(1.5<\mathrm{H} / \mathrm{C}<2$; O/C $\leq 0.3)$ Lipid-like, $(1<\mathrm{H} / \mathrm{C}<2.2 ; 0.1<\mathrm{O} / \mathrm{C}<0.67 ; N \geq 1)$ Protein-like, $(0.7<\mathrm{H} / \mathrm{C}<1.5 ; 0.1<\mathrm{O} / \mathrm{C}<0.67)$ Lignin-like, $(\mathrm{H} / \mathrm{C}>1.5 ; \mathrm{O} / \mathrm{C}>0.67)$ Carbohydrate-like, $(0.2<\mathrm{H} / \mathrm{C}<0.7$; $\mathrm{O} / \mathrm{C} \leq 0.67)$ CAS Condensed aromatic structures, $(0.7<\mathrm{H} / \mathrm{C}$ $<1.5 ; \mathrm{O} / \mathrm{C} \leq 0.1$ ) UHC Unsaturated hydrocarbons (Hockaday et al., 2009). Online databases such as ChEMBL and PubChem were used to tentatively estimate the potential isomeric structures of the most abundant group of molecules identified by FT-ICR MS data. The formulae most represented in each heteroatomic group were matched online and the most common structures selected when similar features were identified. It should be noted that structure identification might not be indicative of the actual isomer configuration.

\section{${ }^{13}$ C-CPMAS NMR Spectroscopy}

A $300 \mathrm{MHz}$ Bruker Avance spectrometer, equipped with a $4 \mathrm{~mm}$ wide-bore MAS probe, was used to run solid-state spectra of the HA sample. Powdered sample was packed into a $4 \mathrm{~mm}$ zirconium rotor, stoppered with a Kel-F cap and spun at a rate of $13,000 \pm 1 \mathrm{~Hz}$. A ${ }^{13} \mathrm{C}-\mathrm{NMR}$ spectrum was acquired through the Cross-Polarization Magic-Angle-Spinning (CPMAS) technique with the following parameters: $2 \mathrm{~s}$ of recycle delay, $1 \mathrm{~ms}$ of contact time, $30 \mathrm{~ms}$ of acquisition time, and 4,000 scans. The spectrum was processed by using both Bruker Topspin Software (v.2.1, Bruker Biospin, Rheinstetten, Germany) and MestReC NMR Processing Software (v.4.8.6.0, Cambridgesoft, Cambridge, Massachusetts, USA). Integration of the chemical shift was performed as follows: (0-45 ppm) AlkylC, (45-60 ppm) Methoxyl-C, (60-95 ppm) O-Alkyl-C, (95110 ppm) O2-Alkyl-C, (110-145 ppm) Aryl-C, (145-165 ppm) O-Aryl-C, (165-210 ppm) Carbonyl-C. Structural indices that provided additional biochemical characterization were calculated as follows: hydrophobicity index, $\mathrm{HB}=(0-45+110-145+$ $145-165 \mathrm{ppm}) /(60-110+165-210 \mathrm{ppm})$, alkylic ratio, Alk$\mathrm{R}=(0-45 \mathrm{ppm}) /(60-110 \mathrm{ppm})$, lignin ratio, $\operatorname{Lig} \mathrm{R}=(45-$ $60 \mathrm{ppm}) /(145-165 \mathrm{ppm})$, aromaticity index, $\mathrm{AI}=(110-165$ $\mathrm{ppm}) /(0-110+165-210 \mathrm{ppm})($ Spaccini and Piccolo, 2007).

\section{Molecular Mixing Model}

Mathematical algorithms of the molecular mixing model (MMM) were used to extract relevant quantitative information from NMR and MS data as described by Baldock et al. (2004) and modified by Hockaday et al. (2009). Briefly, the model uses NMR peak areas to estimate the relative proportion of six components that represent the major biomolecule classes found in natural organic matter to describe the molecular composition of the sample. The six classes correspond to: Carbohydrate, protein, lignin, aliphatic, carbonyl and char. The model is built upon the empirical data obtained for terrestrial and marine environments. The linear combination of the six components allows the model to calculate the best fit to the measured NMR area distribution. As a means of quantitative matching, the MS data obtained by classification of molecular formulae into biochemical categories were used to run the MMM by reverse approach and predict the signal distribution for a ${ }^{13} \mathrm{C}$-CPMAS NMR. In this way, it was possible to compare in a meaningful way the two analytical techniques and assess the degree to which the molecular distribution relates to the elemental composition.

\section{FT-IR ATR Spectroscopy}

An infrared (IR) spectrum was recorded on a Perkin-Elmer Spectrum Two Infrared Spectrometer using an attenuated total reflection (ATR) device equipped with a diamond/ZnSe crystal. About $5 \mathrm{mg}$ HA powder was weighed and put in contact with the crystal by applying a strength of about $150 \mathrm{~N}$ on the sample. The spectrum was acquired by using 32 scans with resolution of $4 \mathrm{~cm}^{-1}$ from the 4,000 to $400 \mathrm{~cm}^{-1}$ region. The sample was 
analyzed 3 times and the average of these spectra was used for data interpretation.

\section{Tomato Plant Pot Experiment and Analysis}

Tomato seeds (Solanum lycopersicum L. cv. Micro-Tom) were surface sterilized in $3 \% \mathrm{NaClO}$ for $10 \mathrm{~min}$ and water rinsed thoroughly before individually sowing in pots containing a mixture of coconut coir and sand (2:1). Plants were grown for three months in a climate-controlled growth chamber set at $28^{\circ} \mathrm{C}$ with a light/dark cycle of $14 / 10 \mathrm{~h}$, light intensity set at $300 \mu \mathrm{mol} \mathrm{m}^{-2} \mathrm{~s}^{-1}$ and relative humidity of $65 \%$. At fifteen days seedlings started receiving nutrition as Hoagland solution with quarter (25), half (50) or full (100) NPK dose and watered at $70 \%$ of water holding capacity. Humic acids were added at the pre-plant stage to a concentration of $80 \mathrm{mg}$ $\mathrm{C} \mathrm{L}^{-1}$. Nutritional dose and HA concentration were selected based on a previous experiment so that a nutritional stress condition was triggered at low nutrient dose (data not shown). A total of six treatments with eight replicates per treatment were arranged in a randomized complete block design. During the experiment plant height was tracked, and chlorophyll content measured by a chlorophyll meter MC-100 (Apogee Instruments, Logan, UT, USA). Chlorophyll fluorescence was determined at noon by using a OS30p+ pulse modulated fluorometer (OptiSciences, Hudson, NH, USA) after leaves were subjected to a dark adaptation period of $20 \mathrm{~min}$, followed by the measure of the ratio $F_{V} / F_{0}$, were $F_{V}$ is the difference between the maximum and minimum fluorescence and $\mathrm{F}_{0}$ is the minimum fluorescence detected after dark adaptation. Actinic light intensity was set to $3,500 \mu \mathrm{mol} \cdot \mathrm{m}^{-2} \cdot \mathrm{s}^{-1}$ according to Vredenberg (2011). At the end of the experiments roots and shoots were separated and fresh and dry weights determined. Tomato yield was evaluated by measuring the number of fruits and the fresh weight. Quality and antioxidant parameters were also assessed. Total acidity expressed as $\mathrm{g} \mathrm{L}^{-1}$ of citric acid was obtained by manual titration of tomato juice extract to a $\mathrm{pH}$ of 8.2 with $0.1 \mathrm{M} \mathrm{NaOH}$. Ascorbic acid was determined according to Nielsen (2017) and total soluble solids (TSS) by means of a MA871 Refractometer (Milwaukee Instruments, Woburn, MA, USA). Lycopene content was determined according to the reduced volumes of organic solvents described by Fish et al. (2002).

\section{Data Analysis}

Experimental data were tested for normality distribution (Shapiro-Wilk test) and the means compared through analysis of variance (ANOVA). Post-hoc test was performed to test the statistical significance (Tukey's HSD test, $P<0.05$ ). Principal component analysis (PCA) was used as an exploratory tool to assess the correlation of variables with HA application. XLStat software (Addinsoft) was used for all statistical analyses.

\section{RESULTS}

\section{ESI FT-ICR MS}

FT-ICR MS analysis yielded 9,331 molecular formulae which were assigned with an RMS of $0.17 \mathrm{ppm}$. The compounds not assigned to a molecular formula represent $10.8 \%$ of the total (No hit), highlighted in red in Supplementary Figure 1. The relative abundance weighted average of the molecular weights was $384 \mathrm{~m} / \mathrm{z}$ with an average of $22 \mathrm{C}$ atoms and 16 equivalent double bonds (DBE) (Supplementary Table 1). The subdivision into groups showed that $\mathrm{CHO}$ formulae were the most abundant (47\%), followed by CHON (33.6\%), CHOS (4.94\%), and CHONS (3.72\%) (Table 1). The first two groups showed a similar average molecular weight which was lower in CHOS and CHONS where a smaller number of carbon atoms was also observed, thus indicating the presence of smaller molecules in the less represented groups. The low average molecular weight supports the hypothesis of supramolecular aggregation of small molecules dynamically associated through hydrogen bonds, $\pi-\pi$ stacking and van der Waals interactions as previously suggested (Piccolo, 2001; Sutton and Sposito, 2005) and reported in heavy oil asphaltenes (Gray et al., 2011; McKenna et al., 2013).

Up to $50 \%$ of the relative abundance (scaled to the $100 \%$ peak in each spectrum) corresponded to species assigned to the $\mathrm{CHO}$ class having 3-10 oxygen atoms and the CHON class having 47 oxygens and 1 nitrogen atom (Table 2). The presence of 15-18 equivalent double bonds suggests the aromatic properties of these molecules. The elemental composition of HA calculated from the FT-ICR data was consistent with the combustion results. S content, however, was partially underestimated.

The Van Krevelen diagram containing all the peaks did not allow an immediate visual evaluation as the high number of identified components were superimposed and dispersed along both coordinates (Figure 1A). However, the comparison of single heteroatomic groups revealed that most of the molecules are grouped in proximity of the $x, y$ intercepts, extending up to values of 0.65 for $\mathrm{O} / \mathrm{C}$ and 0.9 for $\mathrm{H} / \mathrm{C}$, except in the $\mathrm{CHO}$ group (Figures 1B-D).

By assigning the compositional space to areas defined by specific $\mathrm{H} / \mathrm{C}$ and $\mathrm{O} / \mathrm{C}$ ratios, it was possible to group the molecules into typical classes of discrete organic molecules such as lignin, lipids, proteins, carbohydrates, condensed aromatic structures (CAS), and unsaturated hydrocarbons (UHC).

To further simplify the information visualized in the chart, the data reduction of Van Krevelen points was performed by gathering molecules in classes of compounds with the same heteroatomic number (Figure 2). Most of the classes belonging to the group of $\mathrm{CHO}$ molecules fell within the lignin compounds, particularly those with a lower number of oxygens ranging from 3 to 10 oxygen atoms, while those with a greater number of $\mathrm{O}$ atoms, the most abundant ones, lay in the CAS area (Figure 2A).

The classes belonging to the $\mathrm{CHON}$ compounds largely concentrated in the CAS area possessing $1 \mathrm{~N}$ atom and oxygen atoms ranging from 3 to 8 (Figure 2B). On the other hand, heteroatomic compounds showing 1 or $2 \mathrm{~S}$ atoms were distributed more uniformly among compounds belonging to the CAS category, lignin derivatives and protein-derived structures (Figure 2C).

Finally, the compounds showing the largest heteroatomic distribution appeared in the region belonging to the CAS area with a small number of classes representative of more labile structures such as carbohydrates (Figure 2D). 
TABLE 1 | Group distribution of Idaho HA FT-ICR MS spectrum after molecular formula assignment.

\begin{tabular}{|c|c|c|c|c|c|c|c|c|}
\hline Group & $N$ peaks & \% R.A. & Avg m/z & W. Avg m/z & W. Avg C\# & W. Avg DBE & W. Avg H/C & Al \\
\hline $\mathrm{CHO}$ & 4,447 & 47.0 & 409 & 369 & 21 & 16 & 0.81 & 0.58 \\
\hline $\mathrm{CHON}$ & 3,229 & 33.6 & 404 & 362 & 20 & 16 & 0.66 & 0.67 \\
\hline $\mathrm{CHOS}$ & 882 & 4.94 & 343 & 326 & 17 & 13 & 0.76 & 0.73 \\
\hline CHONS & 773 & 3.72 & 385 & 344 & 17 & 15 & 0.99 & 0.65 \\
\hline
\end{tabular}

R.A., Relative abundance; Avg, Average; W. Avg, Weighted average; C\#, Carbon number; DBE, Double bond equivalent; Al, Aromatic index.

TABLE 2 | Parameters for the main class distribution contributing up to $50 \%$ of the relative abundance.

\begin{tabular}{|c|c|c|c|c|c|c|}
\hline Class & $N$ peaks & \% R.A. & W. Avg m/z & W. Avg C\# & W. Avg DBE & W. Avg H/C \\
\hline O6 & 348 & 6.32 & 363 & 21 & 16 & 0.77 \\
\hline $\mathrm{O} 7$ & 339 & 6.31 & 382 & 22 & 16 & 0.74 \\
\hline O5 & 379 & 6.27 & 346 & 21 & 15 & 0.80 \\
\hline O4 & 392 & 5.24 & 336 & 22 & 16 & 0.87 \\
\hline О8 & 297 & 4.70 & 398 & 22 & 16 & 0.75 \\
\hline O9 & 286 & 3.64 & 426 & 23 & 17 & 0.75 \\
\hline N1 O5 & 200 & 3.49 & 352 & 21 & 16 & 0.67 \\
\hline N1 O6 & 189 & 3.47 & 370 & 21 & 16 & 0.64 \\
\hline O3 & 378 & 3.24 & 325 & 22 & 15 & 0.99 \\
\hline N1 O4 & 172 & 3.01 & 325 & 20 & 15 & 0.67 \\
\hline N1 O7 & 183 & 2.44 & 393 & 22 & 17 & 0.65 \\
\hline 010 & 240 & 2.43 & 450 & 23 & 18 & 0.74 \\
\hline
\end{tabular}

R.A., Relative abundance; Avg, Average; W. Avg, Weighted average; C\#, Carbon number; DBE, Double bond equivalent.

The molecular distribution for each class of compounds calculated by the $\mathrm{H} / \mathrm{C}$ and $\mathrm{O} / \mathrm{C}$ ratio are summarized in Figure 3A. The most represented compounds were those falling within the lignin and condensed aromatic structures, quantified at 29.5 and $28.6 \%$, respectively, followed by a smaller proportion in unsaturated hydrocarbons, lipids, proteins, and carbohydrates.

The elemental composition of each biomolecule group is illustrated in Figure 3B. It is interesting to note the contribution of all heteroatomic classes to the CAS, lignin and UHC groups in which $\mathrm{CHO}$ structures add up to $\sim 39-55 \%$, whereas the carbohydrate group mainly contained $\mathrm{CHONS}$ and $\mathrm{CHOS}$ structures but lacked $\mathrm{CHO}$ structures. As expected, $\mathrm{CHON}$ structures are largely associated with proteins. Lipids were almost exclusively composed of $\mathrm{CHO}$ molecules.

By matching FT-ICR molecular formulae by means of online chemical databases, we found that most of the lignin structures corresponding to FT-ICR assignments were represented by flavonoid and isoflavonoid phenolic compounds, some of them falling under bioactive plant and microbial metabolites (Supplementary Table 1). The major contribution came from both the $\mathrm{CHO}$ and $\mathrm{CHON}$ series, even though $\mathrm{N}$-containing compounds belonged to more differentiated classes such as alkaloids, benzamides, and several nitrobenzene analogues in which the polar character of nitro groups confers a strong electron-withdrawing capacity and reactivity. In general, they can be classified as aromatic amines because of their relevant hydrogen-deficiency. Polyphenol-peptide reactions that produce condensed structures are likely to occur naturally. The CHON series occurred primarily in the area delimiting CAS and lignin structures (Figure 2). On the other hand, the CAS group contained mainly $\mathrm{CHO}$ and $\mathrm{CHON}$ formulae. Part of the nitrogen associated with $\mathrm{HS}$ is expected to be released when HA is separated from fulvic acid by acidic hydrolysis of peptide bonds. However, for amino acids directly bonded to phenolic rings, $\mathrm{N}$ may still exist as an acid-insoluble complex, as confirmed by the infrared spectra in the typical absorption of the peptide bond at $1,417 \mathrm{~cm}^{-1}$ (Figure 6), or as part of a heterocyclic ring as a stable $-\mathrm{NH}$ such as in indole (Stevenson, 1994). Condensed aromatic structures were the second most abundant group identified in the FT-ICR data and showed a substantial presence of quinone-derived structures along with alkaloids, flavonoids, and $\mathrm{PAH}$, most of them identified as potentially bioactive compounds of plant, fungal, and bacterial origin (Senthamarai et al., 2003). Interestingly, some of them derive from a marine and freshwater environment and show antimicrobial and antioxidant activity (Namikoshi, 2006; Sturdy et al., 2010). Similarly, the UHC group also contained an abundance of quinone-derived structures where the presence of nitrogen gives pyridine aromatic analogues.

The most abundant structures identified in the lipid group were saturated fatty acids derived from fossilized plant waxes, hydroxy acids, and dicarboxylic acids. It is worth mentioning the large abundance in this list of polyunsaturated arachidonic acid whose inclination to react with molecular oxygen suggests its 


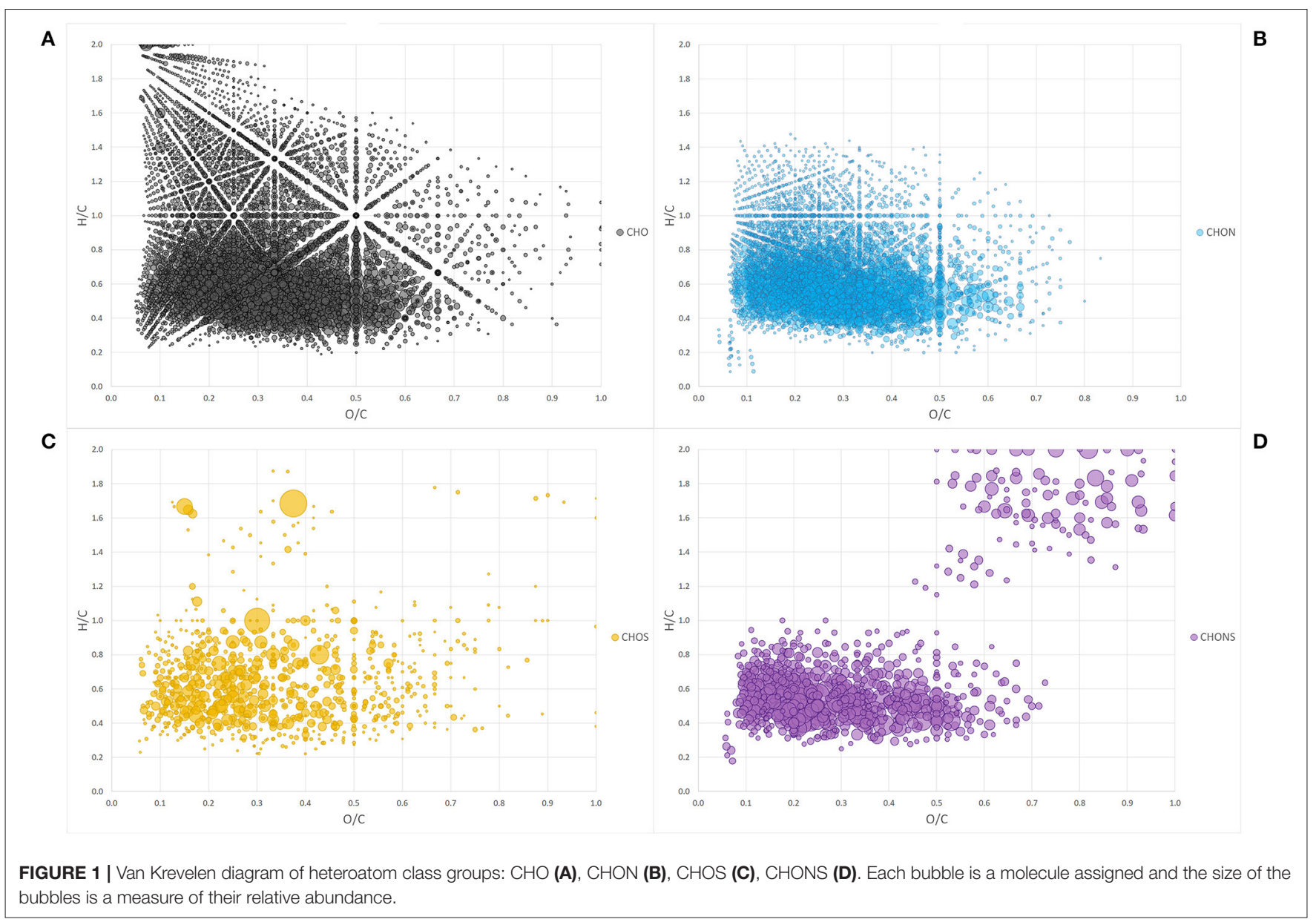

contribution to oxidative stress through the effect on $\mathrm{H}^{+}$channel activity (Henderson et al., 1997).

Protein class contributions were identified mainly in alkaloids, indoles, heterocyclic amines, and amino compounds and possibly bioactive quinoline derived structures, while the carbohydrate group was the less represented in FT-ICR and the most challenging to assign. However, even if small, this group was dominated by CHONS structures, probably sugar sulfates, sulfonates, thiocarbonates, or isothiocyanate derivatives such as glucosinolates, but the lack of specific structural analyses, makes it difficult to draw conclusions about the identity of these compounds.

\section{${ }^{13} \mathrm{C}$ CPMAS NMR}

The ${ }^{13} \mathrm{C}$ CPMAS NMR of the Idaho humic acid is shown in Figure 4. Two broad resonances appear to be predominant, the first in the range 10-45 ppm where the highest peak at $33 \mathrm{ppm}$ was indicative of methyl groups belonging to alkylic structures such as lipidic compounds, and the second in the range of 110$145 \mathrm{ppm}$ where the highest signal appearing at $127 \mathrm{ppm}$ indicated the abundance of protonated aromatic rings.

The relative carbon distribution over the chemical shift is summarized in Table 3. The functional groups most represented were the Alkyl-C and Aryl-C, whose regions accounted for 23.6 and $31 \%$ of the total area, respectively, followed by the O-AlkylC (12.2\%), the O-Aryl-C (9.8\%), and Carbonyl-C (8.8\%) as the most abundant groups. The lower resonances in the O-Alkyl regions, assigned to mono- and polysaccharidic structures mainly derived from plant cellulose, are not resolved in any predominant peak. However, their presence was indicated by the peak at $99 \mathrm{ppm}$ assigned to the anomeric carbons. Methoxyl-C in the range $45-60 \mathrm{ppm}$, which accounted for $8 \%$ of the total area, confirmed the presence of lignin material as the peak at $55 \mathrm{ppm}$ was associated with methoxyl groups substituted on the aromatic core as well as the side chain of lignin monomers. Phenolic compounds added up to lignin aromatic rings as $\mathrm{O}$-substituted $\mathrm{C}$, however this region was mostly overlapped by the Aryl-C region.

Carbonyl-C was visible as a shoulder in the range 165$210 \mathrm{ppm}$ and the peak at $165 \mathrm{ppm}$ was indicative of carboxylated functions in aliphatic chains as well as in protein derived compounds.

Structural indices calculated from the ${ }^{13} \mathrm{C}$ spectrum indicated the mainly aromatic character of the HA where the LigR suggested that preservation of lignin structures happened through the advanced oxidative transformation and stabilization degree of this material. In addition, the AlR and $\mathrm{HB}$ indices highlighted the contribution of aliphatic and olefinic structures to the hydrophobicity degree (Table 3 ). 

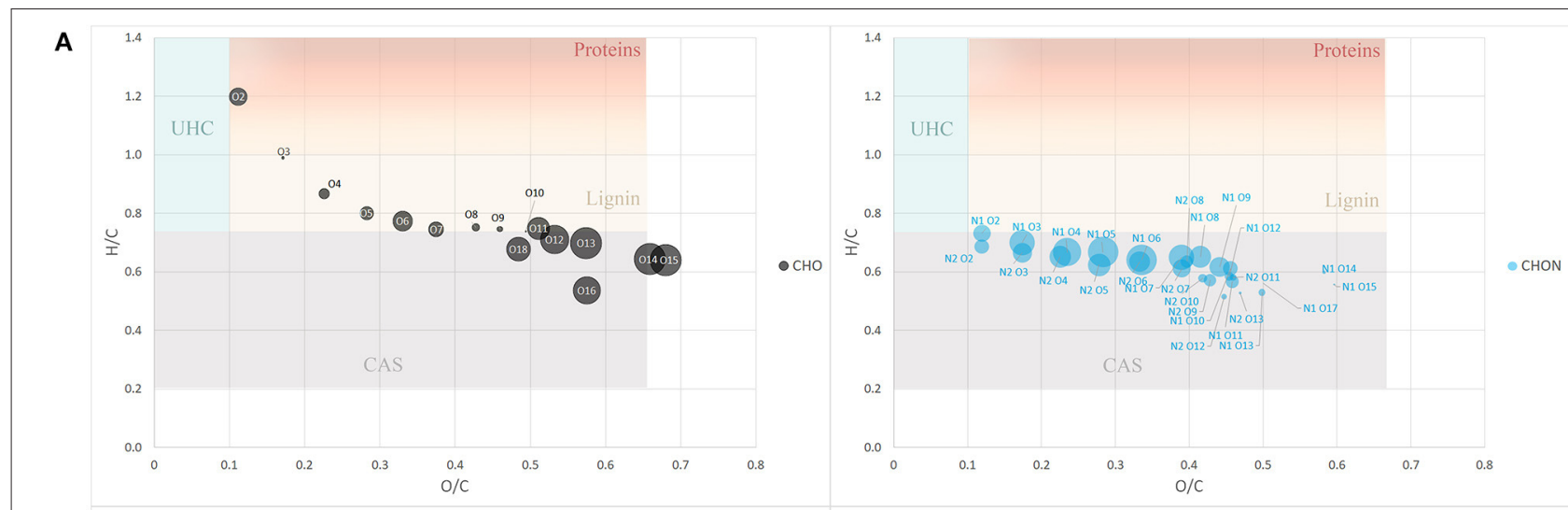

C

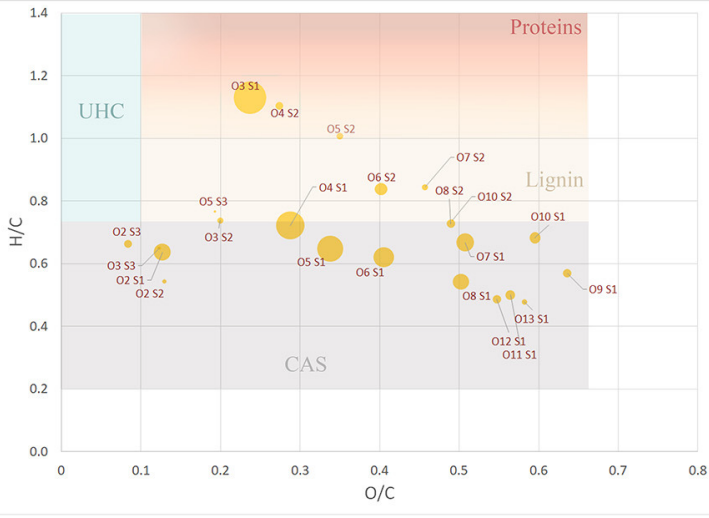

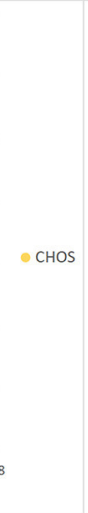

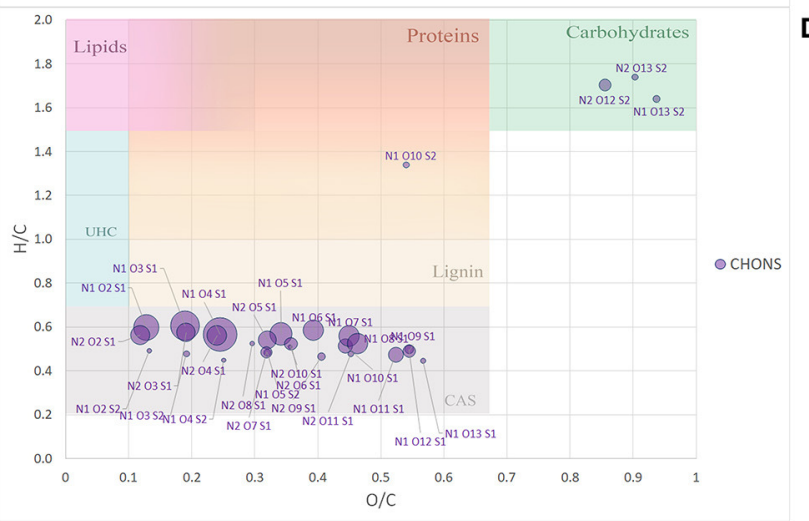

D

FIGURE 2 | Van Krevelen diagram of class group molecules arranged by the same heteroatoms number. $\mathrm{CHO}$ (A), CHON (B), CHOS (C), and CHONS (D). Size of the bubbles is a measure of their relative abundance. Area identified by $\mathrm{H} / \mathrm{C}$ and $\mathrm{O} / \mathrm{C}$ ratios and belonging to different type of organic compounds (proteins, lignins, catbohydrates, lipids, CAS, and UHC) have different background color. Fading colors indicate overlapping of different area.

\section{Molecular Mixing Model: MS and NMR Data Comparison \\ Elemental Composition}

The bulk elemental composition comparison suggested that the FT-ICR values were in good agreement with the elemental analysis in relation to the capacity of this instrument to delve deeper into carbon chemistry (Table 4). Discrepancies arose when heteroatoms were considered as the $\mathrm{N}$ and $\mathrm{S}$ content appeared to be underestimated in the MS data. However, the conservative approach used in the ESI MS analysis was intended to preserve the quality and robustness of the results while keeping the error as low as possible. This was consequently reflected in the molar ratios calculated by each technique and suggested a $\mathrm{H}$ - deficiency in the MS data, possibly due to the exclusion of hydrocarbons with only $\mathrm{C}$ - and $\mathrm{H}$ - from the analysis, which are generally not considered as constituents of organic matter. O/C and N/C ratios were overall in agreement across the analyses as well as the aromaticity index that resulted in a slightly higher value when the FT-ICR result was compared to the NMR mixed model value.

\section{Molecular Distribution}

Data reduction and aggregation along with the molecular mixing model approach allowed the comparison of NMR and FT-ICR data in terms of individual bio-molecule structures. To make the comparison matching accordingly, the NMR carbonyl value was added to the aliphatic value, while the MS UHC value was combined with the lipid group. Finally, the Char classification in the NMR is referred to as CAS in the MS analysis. There was a close agreement of NMR and MS biomolecule groups, except for the carbohydrates class, which was underrated in the FT-ICR results (Figure 5). This trend has been observed previously by other authors and seems to be ascribed to ionization efficiency of this biochemical class (Hockaday et al., 2009). The difference observed in the CAS value between the two techniques can be ascribed to a minor efficiency of cross-polarization technique to correctly represent carbons that are not closely associated with protons, like those of condensed aromatic rings. Consequently, aliphatic carbons could have been preferentially cross-polarized over condensed aromatics and that could have resulted in the underestimation (Kramer et al., 2004).

\section{FT-ATR}

The spectrum of Idaho HA (Figure 6) showed the typical adsorption bands of humic material. The two peaks appearing at 2,920 and $2,853 \mathrm{~cm}^{-1}$ were assigned to both the symmetrical and asymmetrical stretching vibrations of methyl and methylene functions of aliphatic structures, including fatty acids, waxes, higher alkanes and other naturally occurring polyesters. The broad shoulder ranging from 2,500 to $3,500 \mathrm{~cm}^{-1}$ represented 


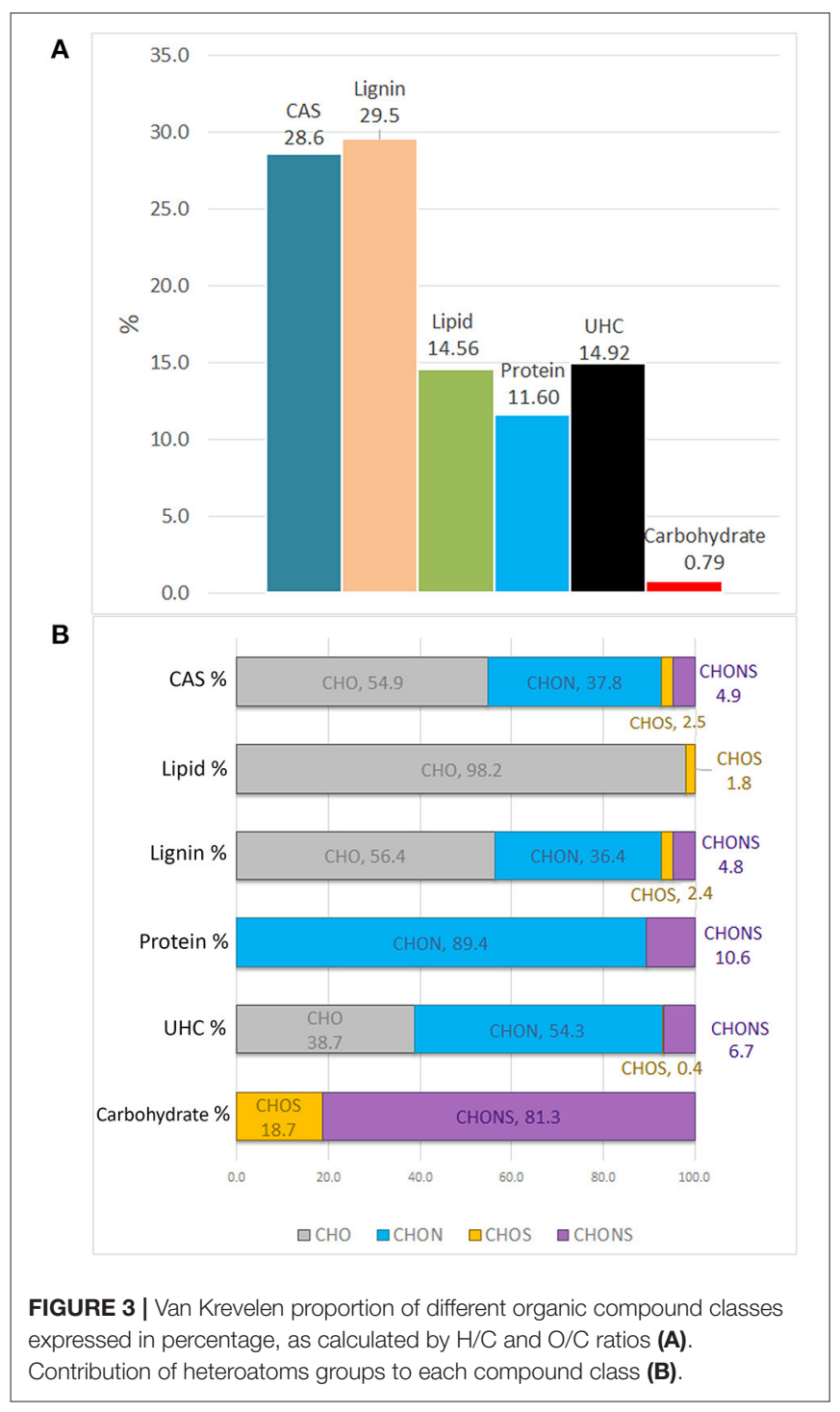

hydroxyl groups belonging to alcohols, phenols, and carboxylic acids. The fingerprint region showed two typical adsorptions at 1,703 and $1,605 \mathrm{~cm}^{-1}$ where the stretching of $\mathrm{C}=\mathrm{O}$ and the vibrations of carbonyl occur, indicating the presence of carboxylic acids, further confirmed by the weak peak at 1,417 $\mathrm{cm}^{-1}$, which can be alternatively attributed to amide II bond stretch. The quite intense peak at $1,198 \mathrm{~cm}^{-1}$ and the shoulder peak appearing at $1,041 \mathrm{~cm}^{-1}$ were assigned respectively to phenolic $-\mathrm{OH}$ of lignin structures and the $\mathrm{C}-\mathrm{O}$ stretching of polysaccharidic compounds, such as cellulose and hemicellulose derivatives. The two peaks in the lower fingerprint region at around 803 and $763 \mathrm{~cm}^{-1}$ were assigned to $-\mathrm{CH}$ vibrations of substituted benzene rings belonging to both aromatic and phenolic derivatives.

\section{Plant Growth Bioassay}

To test the biological activity of the HA extract, plant morphological traits were investigated. The final goal of the application of HA is the positive economic impact on production. Therefore, yield and fruit quality parameters were also evaluated.

Plants grown under HA treatment showed the best general performances, especially when NPK nutrient supply was reduced to half or a quarter in combination with HA application. The differences observed in shoot biomass showed that the largest value was produced by the $50 \mathrm{HA}$ treatment, followed by 25 HA treatment (Table 5). Root biomass was generally positively affected by the application of HA. Root weight, in particular the dry weight, was significantly affected by the presence of HA. The best overall performance was displayed by the $50 \mathrm{HA}$ treatment. Even though the HA supplied under full nutrition resulted in a detrimental effect for several parameters observed, root growth was still positively influenced by the addition of the extract. Chlorophyll content showed an increasing trend when HA was supplied at increasing nutritional doses, however, the differences were not statistically significant. A decrease in chlorophyll fluorescence is an indicator of an ongoing physiological stress. As expected, the control treatment under full nutrition showed the least stress condition, followed by 25 $\mathrm{HA}$ and $50 \mathrm{HA}$ that showed the ability to better cope with the stress when compared to the relative controls. Conversely, the drastic decrease in the fluorescence signal measured for $100 \mathrm{HA}$ treatment indicated a reduced photosynthetic efficiency (Table 5).

Tomato production and quality assessment results are summarized in Table 5. Yield obtained by HA-treated plants showed an increased number of tomatoes produced, up to +19 and $+16 \%$ in $25 \mathrm{HA}$ and $50 \mathrm{HA}$ treatments, respectively. The trend was not continued when full nutrition was supplied, in which the application of HA decreased the numbers of tomatoes by $13 \%$ when compared to the relative control. However, tomato fresh weight was increased in all HA treatments, up to a $+24 \%$ in the 25 HA treatment.

The fruit quality assessment involved the analysis of acidity, the total soluble solid content (i.e., Brix) and the antioxidant activity measured by lycopene and ascorbic acid production (Table 5). Total acidity increased as a result of the application of $\mathrm{HA}$ at half and full nutritional strength, while the soluble solid content increased in the $25 \mathrm{HA}$ and $100 \mathrm{HA}$ treatments, +12 and $+24 \%$, respectively, as compared to non-treated plants. Lycopene content increased significantly only in the $50 \mathrm{HA}$ and $100 \mathrm{HA}$ treatments. Except for the full nutritional level (100 HA) where there was a significant decrease, the application of HA increased the ascorbic acid concentration up to $10 \%$ in the $50 \mathrm{HA}$ treatment as compared to respective control.

The data reduction through principal component analysis allowed the determination of the variables most influenced by the HA application. Humic treatments were clearly separated from the controls along the first principal component that explained $58.8 \%$ of variability (Figure 7 ). All the variables were spread mostly along the second principal component and showed a positive correlation with $25 \mathrm{HA}$ and $50 \mathrm{HA}$ treatments. Root dry weight was the strongest correlating parameter, while chlorophyll, root fresh weight and ascorbic acid appeared less important for the purpose of biostimulation. 


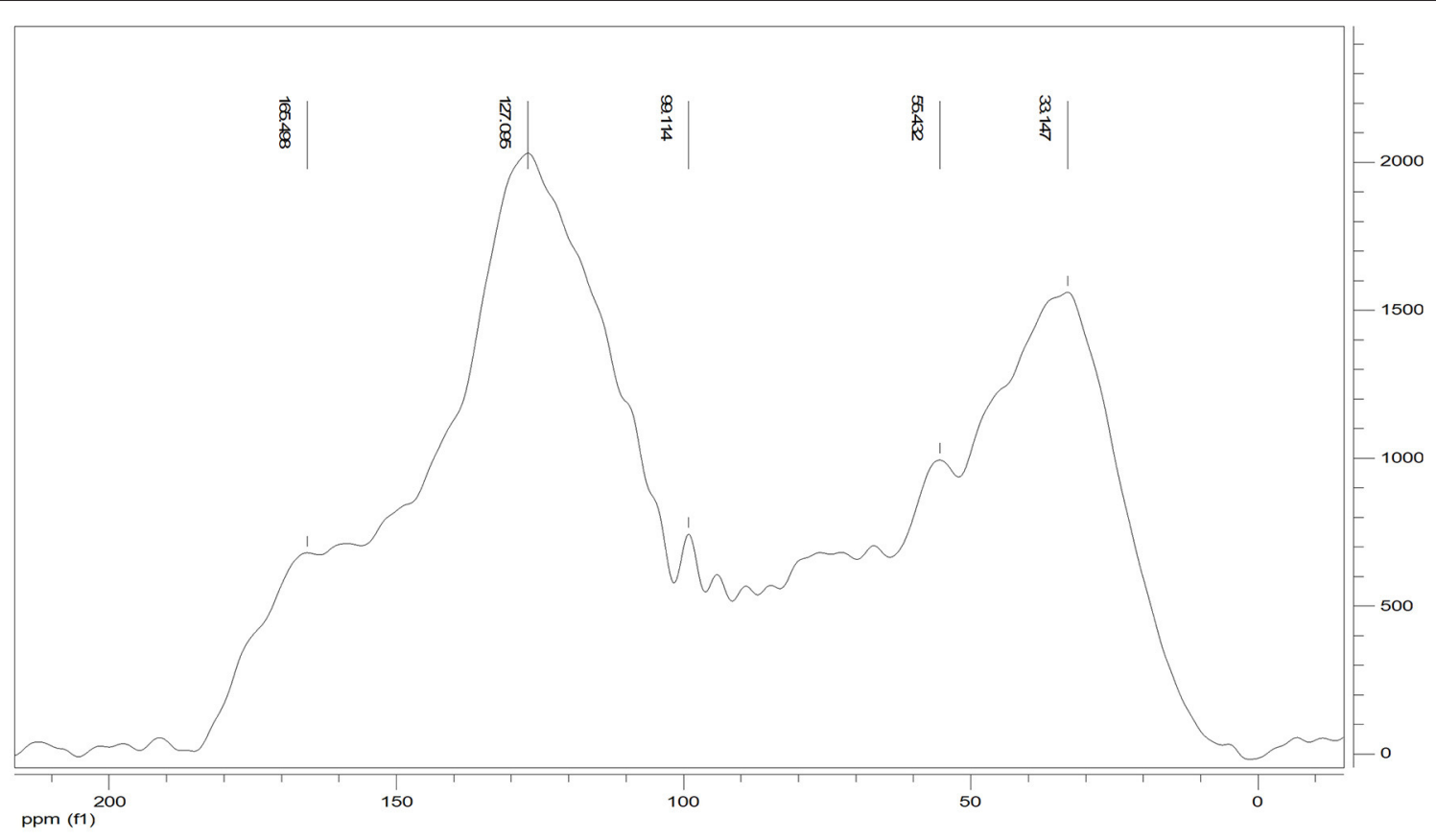

FIGURE $4 \mid{ }^{13} \mathrm{C}$ CPMAS NMR spectrum of Idaho HA.

TABLE 3 | Relative contribution (\%) of main C structures over chemical shift regions (ppm) calculated from ${ }^{13} \mathrm{C}$ CPMAS NMR of Idaho HA sample and structural indices derived from spectral areas.

\begin{tabular}{|c|c|c|c|c|c|c|c|c|c|c|c|}
\hline Sample & $\begin{array}{c}\text { Carbonyl-C } \\
210-165\end{array}$ & $\begin{array}{l}\text { O-Aryl-C } \\
165-145\end{array}$ & $\begin{array}{c}\text { Aryl-C } \\
145-110\end{array}$ & $\begin{array}{c}\text { O2-Alkyl-C } \\
110-95\end{array}$ & $\begin{array}{c}\text { O-Alkyl-C } \\
95-60\end{array}$ & $\begin{array}{c}\text { Methoxyl-C } \\
60-45\end{array}$ & $\begin{array}{c}\text { Alkyl-C } \\
45-10\end{array}$ & HB & AIR & LigR & Al \\
\hline IDHA & 8.8 & 9.8 & 31.0 & 6.7 & 12.2 & 8.0 & 23.6 & 1.8 & 1.25 & 0.81 & 0.5 \\
\hline
\end{tabular}

HB, Hydrophobicity index; AlR, Alkylic ratio; LigR, Lignin ratio; Al, Aromaticity index.

TABLE 4 | Elemental composition of Idaho HA as determined by elemental analysis (EA), FT-ICR ESI MS, ${ }^{13} \mathrm{C}$ CPMAS NMR (through molecular mixing model MMM).

\begin{tabular}{lcccccccccc}
\hline & $\mathbf{C} \%$ & $\mathbf{H} \%$ & $\mathbf{O} \%$ & $\mathbf{N} \%$ & $\mathbf{S} \%$ & H/C & O/C & N/C & S/C & Al \\
\hline EA & 50.1 & - & - & 2.03 & 1.59 & - & - & 0.04 & 0.032 \\
FT-ICR & 50.2 & 32.9 & 15.2 & 1.38 & 0.29 & 0.65 & 0.30 & 0.03 & 0.006 & 0.66 \\
${ }^{13}$ C NMR MMM & - & - & - & - & - & 1.18 & 0.34 & 0.08 & - & 0.5
\end{tabular}

\section{DISCUSSION}

Optimization of nutrient use efficiency represents an important strategy to reduce the environmental cost generated by harmful contamination of groundwater and atmosphere that mineral fertilizers produce when used in excess to maximize crop production (Conley et al., 2009). The use of HS as biostimulant represents a cost-effective and environmental-friendly tool to improve nutrient uptake by promoting sustainable agricultural practices. Indeed, HS affect nutrient complexation and act as natural chelates (Garcia-Mina et al., 2004; Tomasi et al., 2014) but they also induce plant metabolism changes. HS stimulate active proton extrusion from the root plasma membrane by the activity of $\mathrm{H}^{+}$-ATPase resulting in the generation of a transmembrane potential involved in the cell elongation and active uptake of nutrients (Varanini et al., 1993; Canellas et al., 2002; Zandonadi et al., 2007; Jannin et al., 2012). More recently it has been observed that HS performances increase when a stress condition is present. Jindo et al. (2016) demonstrated that application of $\mathrm{HS}$ in the presence of low phosphorus availability induces high-affinity $\mathrm{P}_{\mathrm{i}}$ transporters in plant roots thereby enhancing P uptake. Tavares et al. (2019) found that HA stimulated $\mathrm{NO}_{3}^{-}$uptake after $96 \mathrm{~h}$ of $\mathrm{N}$ deprivation. Additionally, the chemical nature of HS that differs for each source plays a key-role and often leads to practical ineffective results. In this SAR study the biostimulant activity of an ore-extracted and 
- FT-ICR $\quad$ 13C NMR

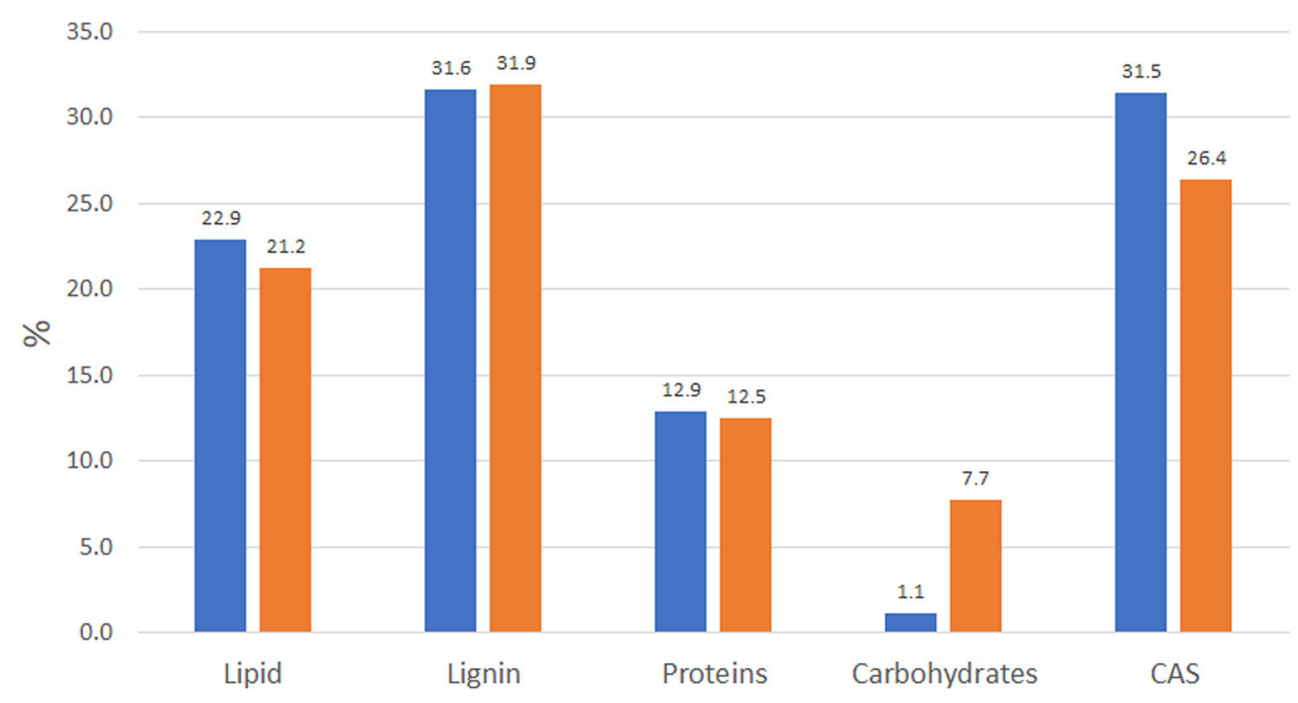

FIGURE 5 | Idaho HA molecular distribution into the main biomolecule structures as observed by FT-ICR and ${ }^{13} \mathrm{C}$ NMR. Data computed through MMM for both analyses.

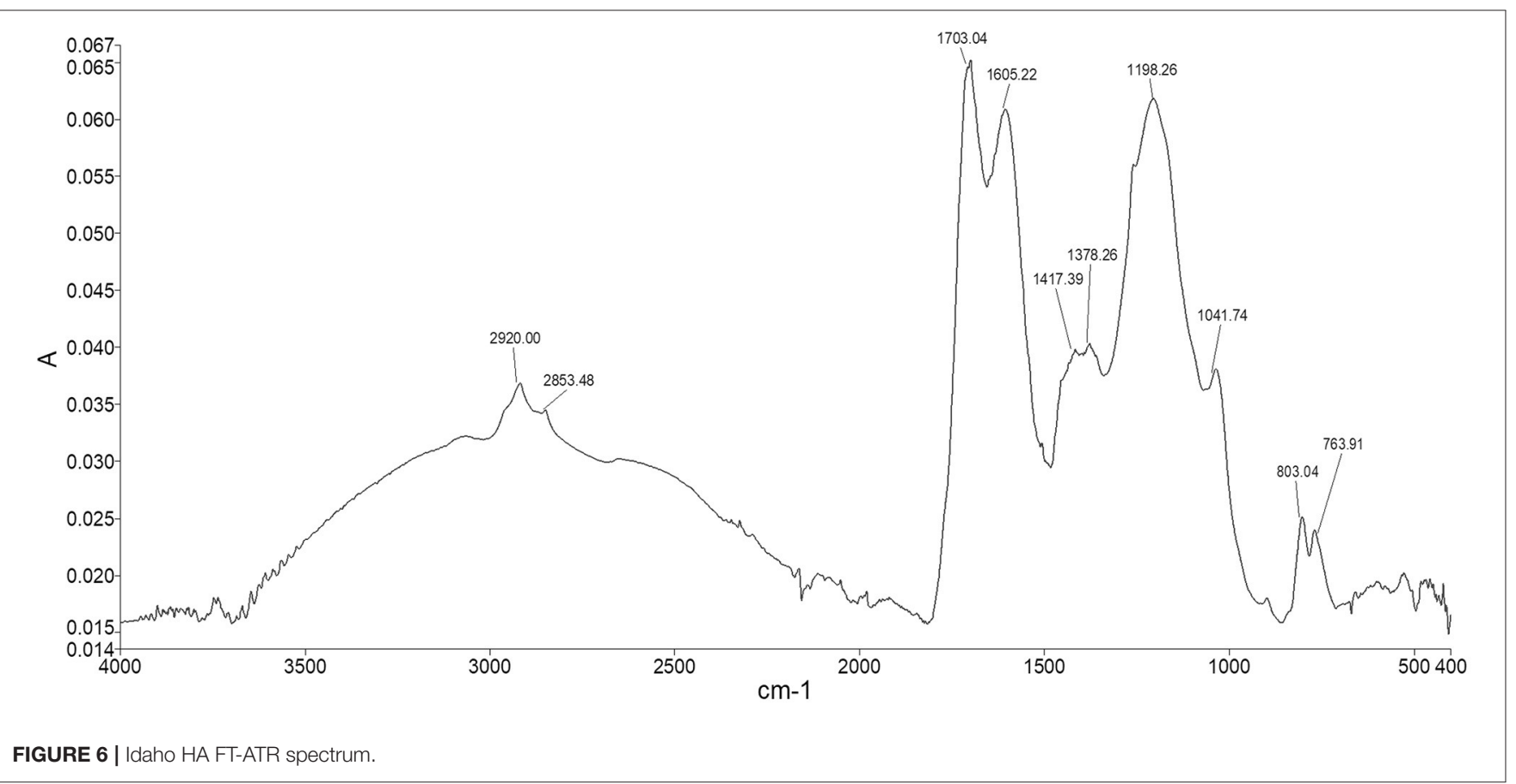

purified HA was evaluated in a tomato pot experiment and the HA chemical proprieties were characterized by means of highresolution $\mathrm{MS},{ }^{13} \mathrm{C} \mathrm{NMR}$, and FT-IR. The chemical nature of HA was further analyzed for the recognition of specific biochemical structures potentially involved in tomato plant morphological and productivity responses, including an increase in defense mechanism parameters.

The application of HA confirmed its ability to stimulate tomato plant growth. HA treated plants yielded more tomatoes than control plants when combined with lower nutritional dose. Comparison of the control under $50 \%$ of nutritional dose with the HA treatment at $25 \%$ of nutrition supplied showed a similar production rate and similar photosynthetic activity, indicating the ability of HA to alleviate the stress condition and to partially reduce the amount of fertilizer required to obtain comparable results.

Tomato fruit quality improvements were also reported in all HA treatments. Although the application of HA was less effective under full nutrition in terms of some morphological parameters in this treatment, HA may have caused the plants to shift to an 
TABLE 5 | Plant morphological mean data, tomatoes yield, and quality parameters.

\begin{tabular}{|c|c|c|c|c|c|c|c|c|c|c|c|c|c|}
\hline Treatment & $\begin{array}{c}\mathrm{H} \\
\mathrm{cm}\end{array}$ & $\begin{array}{c}\mathrm{CHL} \\
\mu \mathrm{mol} \mathrm{\textrm {m } ^ { 2 }}\end{array}$ & $\begin{array}{c}\text { CHL FL } \\
\text { Fv/Fo }\end{array}$ & $\begin{array}{c}\text { SHOOT FW } \\
\mathrm{g}\end{array}$ & $\begin{array}{c}\text { SHOOT DW } \\
\mathrm{g}\end{array}$ & $\begin{array}{c}\text { ROOT FW } \\
\text { g }\end{array}$ & $\begin{array}{c}\text { ROOT DW } \\
\mathrm{g}\end{array}$ & TOM N & $\begin{array}{c}\text { TOM FW } \\
\text { g }\end{array}$ & $\begin{array}{c}\text { TA } \\
\text { g/L citric a. }\end{array}$ & $\begin{array}{l}\text { TSS } \\
\text { Brix }\end{array}$ & $\begin{array}{c}\text { AsA } \\
\mathrm{mg} / \mathrm{g} \mathrm{FW}\end{array}$ & $\begin{array}{c}\text { Lycopene } \\
\text { mg/100 g FW }\end{array}$ \\
\hline 25 & 6.85 & 401.9 & 2.95 & 7.76 & 1.73 & 4.45 & 0.51 & 13 & 3.25 & 4.0 & 5.5 & 0.46 & $11.5^{\star}$ \\
\hline 100 & 7.36 & 423.0 & $3.02^{\star}$ & $9.10^{\star}$ & 1.88 & 5.14 & 0.66 & 32 & 5.65 & 4.1 & 5.4 & $0.52^{*}$ & 11.8 \\
\hline $25 \mathrm{HA}$ & 7.39 & 425.3 & $3.00^{\star}$ & $9.93^{\star}$ & $2.07^{\star}$ & 3.94 & $0.79^{\star}$ & 16 & $4.29^{\star}$ & 3.9 & $6.2^{*}$ & $0.49^{\star}$ & 10.6 \\
\hline
\end{tabular}

H, height; CHL, Chlorophyll; CHL FL, Chlorophyll fluorescence; FW/DW, Fresh/Dry weight; TOM N, Tomatoes number; TA, Total acidity; TSS, Total soluble solids; AsA, Ascorbic acid. Significant difference at $P<0.05$ (Tukey's test) are indicated by asterisk.

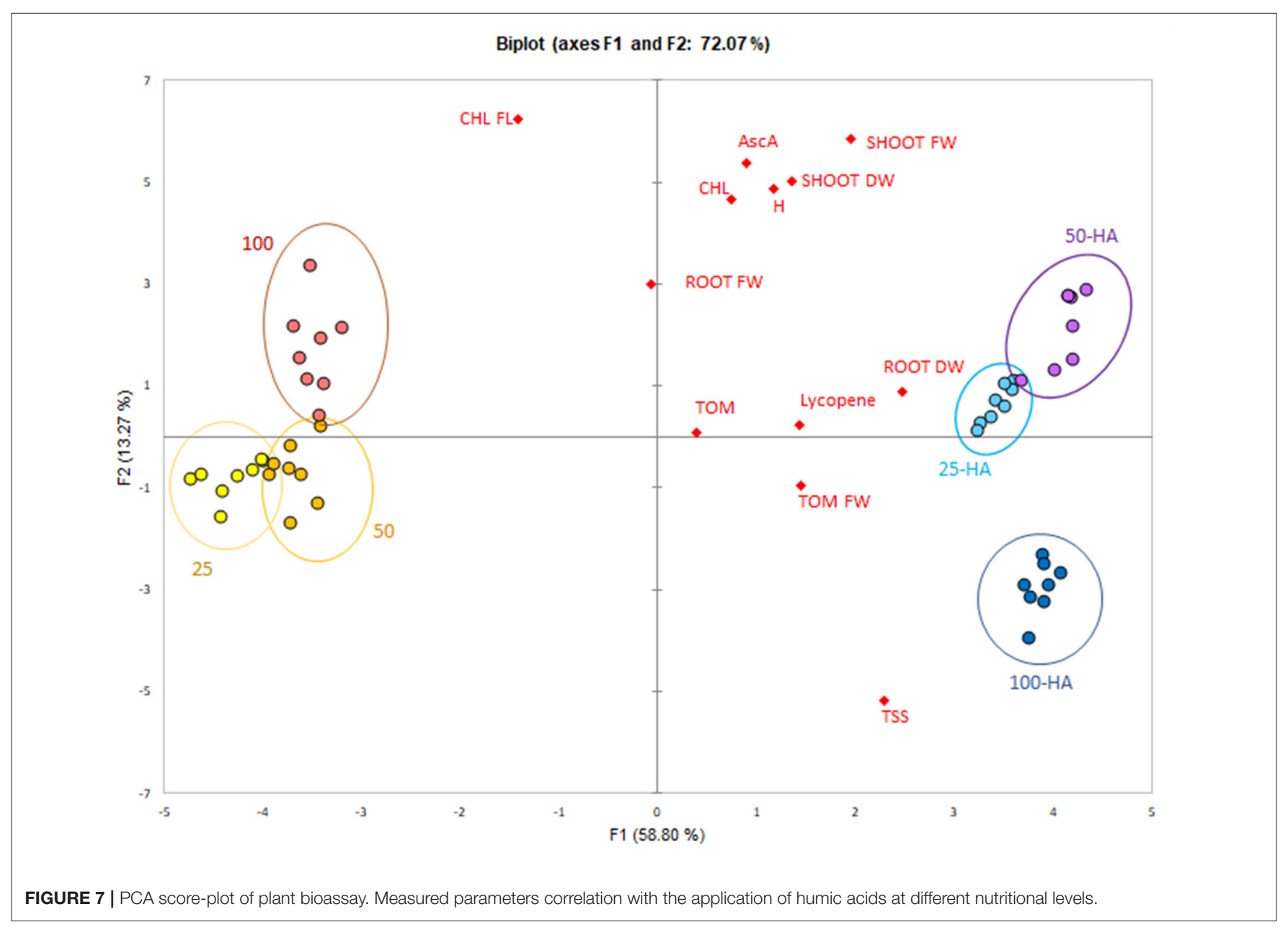

energy conservation strategy that entailed less vegetative growth but promoted mainly fruit development. In fact, even if tomatoes produced in HA100 were slightly less in number than control, their fresh weights were larger by $10 \%$. This conclusion was also supported by the content of total soluble solids, lycopene, and total acidity that in $100 \mathrm{HA}$ tomatoes outperformed the respective control.

The application of HA overall increased the content of measured antioxidants as a result of plant defense system activation. Ascorbic acid, which as the primary plant antioxidant contributes to the reduction of the oxidative damage, may have allowed a stronger response of HA treated plants to the nutrient stress condition. When compared to relative controls, the HA treatments showed a significant lycopene increase only at higher nutritional input. The increased stress due to deficient nutrition is supposed to increase the antioxidant content at lower NPK supply, but conversely to what expected, lycopene increased as nutritional dose increases, in both controls and HA 
treatments. Our results are in accordance with Koleška et al. (2017). The higher K and P fertilization could be potentially responsible for the described trend because they have been reported to positively influence lycopene content in tomato as their supply is increased (Zdravković et al., 2004; Ramírez et al., 2009).

The FT-ICR MS analysis of the HA helped provide an understanding of the composition and distribution of major biomolecule classes present. This ore-extracted HA consisted of more than 10,000 small molecules with an average $\mathrm{m} / \mathrm{z}$ of 384 and are representative of plant and microbial aromatic biomolecule derivatives. Together with a marked presence of aliphatic compounds, these components confer on this HA a distinctive aromatic and hydrophobic character. The ${ }^{13} \mathrm{C}$ CPMAS NMR supported this outcome showing that relative carbon distribution is concentrated mostly in the aliphatic and aromatic region where the presence of peaks at 56,127, and $165 \mathrm{ppm}$ have been previously associated with lateral root stimulation bioactivity (Aguiar et al., 2013). On the other hand, it highlighted the preservation of a modest carbohydrate component that was not found in the FT-ICR MS. The molecular mixing model was used to predict the molecular allocation of biomolecules by applying FT-ICR MS data to the model and comparing the results to the NMR data. The model showed a close match in the distribution of biomolecules, except for carbohydrates, confirming the preferential ionization, in the ICR cell, of some classes of compounds such as CAS and lipids. Nonetheless, the correspondence in all the other groups overall proved the validity of the model comparison.

Online database searches of the molecular formulae identified several bioactive molecules belonging to the lignin derived flavonoids class, quinone-derived structures, and other molecules belonging to CAS and lipids that are potentially involved in the oxidative stress modulation.

Flavonoids are a big family of phytochemicals involved in the plant defense mechanism while coping with a stress condition (Cetinkaya et al., 2017; Trejo-Téllez et al., 2019). They are synthesized through the phenylpropanoid pathway and exhibit ROS scavenging properties assisting plants in tolerating and escaping external biotic and abiotic stresses (Treml and Šmejkal, 2016). As their role as antioxidants is widely recognized (Pietta, 2000), their occurrence in this humic extract supports the biostimulant action that HA exert on plant fitness. However, they can also be involved in priming plant stress machinery as described by Canellas et al. (2020).

Several authors described the prooxidant and antioxidant properties of phenols, alkaloids, and quinones (Azam et al., 2003; Pietsch et al., 2011; Kurutas, 2015). Polyphenols are considered antioxidants, but they not only might undergo oxidative reactions, but when applied externally, their allelochemical biological role and negative impact on target organisms should be considered. These includes impacts such as ROS generation, inhibition of cell division and reduced photosynthetic rates, among others. Secondary metabolites and particularly phenols can often demonstrate prooxidant activity by releasing a hydrogen atom and producing a reactive semiquinone radical capable of reducing oxygen to $\mathrm{O}_{2}^{-}$which can be further converted to other detrimental ROS including $\mathrm{H}_{2} \mathrm{O}_{2}$ and ${ }^{\circ} \mathrm{OH}^{-}$ by scavenging of other phenols (Grace, 2005; Gniazdowska et al., 2015).

Quinones on the other hand can act as prooxidant and have been proposed as potentially responsible for triggering the ROS production in plant, by acting as electron shuttles due to their oxidizing/reducing capabilities (Lamar, 2010; Lv et al., 2018). However, the antioxidant function of isoprenoid quinones has been recently described by Kruk et al. (2016). They have, indeed, an important biological role as redox co-enzymes and vitamin constituents. Zhang et al. (2018) demonstrated that HA contained redox-active groups and exhibited redox potentials between -0.36 and $-0.28 \mathrm{~V}$ suggesting their role as redox mediator in enhancing multiple microbial reductions, thereby affecting various biogeochemical processes. Nonetheless, Zykova et al. (2018) attributed the radical scavenging property of several HA to the presence of condensed aromatic structures such as semi-quinone type and phenoxyl type radicals.

The presence in HA of molecules that can act transiently as antioxidant or prooxidant depending on the environmental constraints, could explain, at least in part, the bioactivity effect through the modulation of ROS accumulation in plant. Despite the damage that ROS exposure might have in the oxidative process, ROS have an important role as signaling molecules, often leading to the conferment of tolerance to environmental stresses (Balasubramaniyam, 2015). Whether the exposure to stress promotes toxicity or acclimation strategy depends on the homeostasis balance between ROS production and ROS scavenging that eventually produces a shift in the regulatory role of ROS from cell signaling to the negative physiological effects (García et al., 2016a).

HS have been found to increase the ROS levels by acting as a mild stressor by triggering the plant defense system. García et al. (2012) described the increase of ROS in rice roots as a consequence of HA application. Similarly, Mehrasbi et al. (2018) found that HA affected ROS production in algae. However, the pre-teatment with HA has been found to mitigate the presence of major abiotic stresses induced by PEG (García et al., 2016b) as well as salinity, drought and heavy metals (Canellas et al., 2020), resulting in higher transcription level of genes involved in stress perception.

All the molecules found in this study could be involved in both the determination of a eustress, where the final effect is somehow beneficial for the plant, or in the establishment of a distress, leading to detrimental and irreversible tissue damage (Vargas-Hernandez et al., 2017).

In our study, plants under nutritional stress performed better when HA was supplied, while plants at full nutrition were not showing a clear advantage from HA application, which might have behaved as a stressor when no other stress was present. On the other hand, all HA treatments showed faster adaptation to the stress condition, particularly when nutrient deficiency occurred. The resulting increased nutrient accumulation and growth of tomato seedlings by application of humic under limited nutrient availability solution was reported by David et al. (1994) and supports our observations. Indeed, the increased root biomass observed was indicative of a better nutrient uptake efficiency and 
could have resulted from ROS sensitive signaling response to nutrient deprivation that leads to cell-wall relaxation and root growth (Schachtman and Shin, 2007), a process strictly correlated to the activation of plasma membrane $\mathrm{H}^{+}$ATPase reported by several authors (Nardi et al., 2017; Tavares et al., 2017). This hypothesis is in accordance with Cordeiro et al. (2011) that found ROS level increased in the maize root apex upon HA application and a higher transcription of catalase antioxidant enzyme when nitrogen supply was low.

Because the final effect of HS is not solely the consequence of the presence of a single molecule but relies on the complex mix of constituents, how the final effect on plant is modulated is still difficult to predict, but it is likely to be associated with the emerging properties defined by the interaction with plant defense system and the biochemical environment. In fact, lignin, and CAS derived molecules can participate in electron transfer reactions either as donors or acceptors, depending on the presence or absence of specific functional groups. For example, electron transfer mediated by one phenolic hydroxyl group can lead to an oxidized radical, while the presence of two hydroxyl groups on catechol can reduce $\mathrm{H}_{2} \mathrm{O}_{2}$ to $\mathrm{H}_{2} \mathrm{O}$. However, if ROS are not present, the catechol can reduce molecular oxygen to $\mathrm{H}_{2} \mathrm{O}_{2}$, while the presence of ROS drives the process toward the scavenging reactions as long as homeostasis restoration is achieved (Hadacek et al., 2011). The role of HS electron accepting capacity has been investigated by Yang et al. (2016) who found that quinone moieties were responsible for the high reducing ability of low molecular weight HA such as the ones described in our study. Lv et al. (2018) demonstrated that polyphenol-like compounds with medium oxygen content were the major compounds acting as electron donors in HS. Furthermore, polyphenols such as flavonoids can be involved in nutrient uptake as they form stable complexes with $\mathrm{Fe}$ and $\mathrm{Al}$ present in insoluble $\mathrm{Fe}$ - and Al-phosphates thereby increasing the $\mathrm{P}$ solubility for plant uptake (Cesco et al., 2010). Nonetheless, they can also prevent microbial degradation of extracellular phosphatases and organic acids released by roots as a response to nutritional deficiencies (Neumann and Römheld, 2007).

Based on our results, here, we suggest that the balance of flavoinoids and quinones found in the humic extract could have positively modulated ROS signaling involved in plant nutrient uptake and therefore triggered the biostimulant effect observed. While the understanding of mode of action will require further investigation, plant pre-conditioning with HS might represent an important determinant in the adaptive plant defense response and an effective strategy to improve nutrients management and plant productivity.

\section{CONCLUSION}

The outcomes of this study highlighted the role of $\mathrm{HA}$ in enhancing nutrient efficiency uptake. The application of HA at low NPK supply improved tomato yield and plant ability to cope with nutritional stress. Chemical composition revealed the presence of both antioxidants and prooxidant molecules such as flavonoids and quinones and suggested their role as modulators of ROS level in plant by priming plant defense systems and resulting in increased root exploration and antioxidant production. Our results proved that use of HA ultimately leads to a fast and effective response to nutrient deficiency based on increases in plant morphology and productivity.

The implementation of in silico technologies represents a valid tool and a promising strategy where combinations of ultra-high mass resolution and complementary techniques will allow a more extensive understanding of molecular composition of HS from different source environments.

\section{DATA AVAILABILITY STATEMENT}

The original contributions presented in the study are included in the article/Supplementary Material, further inquiries can be directed to the corresponding author/s. FT-ICR MS data is publicly-available on the Open Science Framework through DOI: $10.17605 / O S F . I O / T F 7 Q B$.

\section{AUTHOR CONTRIBUTIONS}

HM and RL conceptualized and designed the study. HM performed the experimental work, the plant experiment, the analytical data analysis, and statistical tests. AM supported the FT-ICRMS data interpretation. RF did the elemental analysis. HM wrote the manuscript. RL and AM supervised the article. All authors approved the submitted version.

\section{FUNDING}

The authors declare that this study received funding from Bio Huma Netics, Inc. The funder was not involved in the study design, collection, analysis, interpretation of data, the writing of this article. It was involved in the decision to submit it for publication.

\section{ACKNOWLEDGMENTS}

A portion of this work was performed at the National High Magnetic Field Laboratory, which is supported by the National Science Foundation Division of Chemistry and Division of Materials Research through Cooperative Agreement No. DMR1644779 and the state of Florida.

\section{SUPPLEMENTARY MATERIAL}

The Supplementary Material for this article can be found online at: https://www.frontiersin.org/articles/10.3389/fpls.2021. 660224/full\#supplementary-material

Supplementary Figure 1 | Idaho HA FT-ICR spectrum. "No hit" highlighted in red (A). Distribution of molecular weights vs. intensity for the different heteroatom groups (B). 


\section{REFERENCES}

Aguiar, N. O., Novotny, E. H., Oliveira, A. L., Rumjanek, V. M., Olivares, F. L., and Canellas, L. P. (2013). Prediction of humic acids bioactivity using spectroscopy and multivariate analysis. J. Geochem. Explor. 129, 95-102. doi: 10.1016/j.gexplo.2012. 10.005

Azam, S., Hadi, N., Khan, N. U., and Hadi, S. M. (2003). Antioxidant and prooxidant properties of caffeine, theobromine and xanthine. Med. Sci. Monit. 9, BR325-BR330.

Azcona, I., Pascual, I., Aguirreolea, J., Fuentes, M., García-Mina, J. M., and Sánchez-Díaz, M. (2011). Growth and development of pepper are affected by humic substances derived from composted sludge. J. Plant Nutr. Soil Sci. 174, 916-924. doi: 10.1002/jpln.201000264

Balasubramaniyam, A. (2015). Hormetic dose response as the paradigm of plant response to stress. Int. J. Plant Biol. Res. 3, 1037.

Baldock, J. A., Masiello, C. A., Gelinas, Y., and Hedges, J. I. (2004). Cycling and composition of organic matter in terrestrial and marine ecosystems. Mar. Chem. 92, 39-64. doi: 10.1016/j.marchem.2004.06.016

Beu, S. C., Blakney, G. T., Quinn, J. P., Hendrickson, C. L., and Marshall, A. G. (2004). Broadband phase correction of FT-ICR mass spectra via simultaneous excitation and detection. Anal. Chem. 76, 5756-5761. doi: 10.1021/ac04 $9733 \mathrm{i}$

Blakney, G. T., Hendrickson, C. L., and Marshall, A. G. (2011). Predator data station: a fast data acquisition system for advanced FT-ICR MS experiments. Int. J. Mass Spectrom. 306, 246-252. doi: 10.1016/j.ijms.2011.03.009

Brown, T. L., and Rice, J. A. (2000). Effect of experimental parameters on the ESI FT-ICR mass spectrum of fulvic acid. Anal. Chem. 72, 384-390. doi: $10.1021 /$ ac9902087

Canellas, L. P., Canellas, N. O. A., Irineu, L. E. S. D. S., Olivares, F. L., and Piccolo, A. (2020). Plant chemical priming by humic acids. Chem. Biol. Technol. Agric. 7, 1-17. doi: 10.1186/s40538-020-00178-4

Canellas, L. P., Olivares, F. L., Aguiar, N. O., Jones, D. L., Nebbioso, A., Mazzei, P., et al. (2015). Humic and fulvic acids as biostimulants in horticulture. Sci. Hortic. 196, 15-27. doi: 10.1016/j.scienta.2015.09.013

Canellas, L. P., Olivares, F. L., Okorokova-Façanha, A. L., and Façanha, A. R. (2002). Humic acids isolated from earthworm compost enhance root elongation, lateral root emergence, and plasma membrane $\mathrm{H}+$-ATPase activity in maize roots. Plant Physiol. 130, 1951-1957. doi: 10.1104/pp. 007088

Cesco, S., Neumann, G., Tomasi, N., Pinton, R., and Weisskopf, L. (2010). Release of plant-borne flavonoids into the rhizosphere and their role in plant nutrition. Plant Soil 329, 1-25. doi: 10.1007/s11104-009-0266-9

Cetinkaya, H., Kulak, M., Karaman, M., Karaman, H. S., and Kocer, F. (2017). "Flavonoid accumulation behavior in response to the abiotic stress: can a uniform mechanism be illustrated for all plants?," in Flavonoids-From Biosynthesis to Human Health, ed G. C. Justino (Rijeka: IntechOpen), 151-165.

Conley, D. J., Paerl, H. W., Howarth, R. W., Boesch, D. F., Seitzinger, S. P., Karl, E., et al. (2009). Controlling eutrophication: nitrogen and phosphorus. Science 123, 1014-1015. doi: 10.1126/science. 1167755

Cordeiro, F. C., Santa-Catarina, C., Silveira, V., and de Souza, S. R. (2011). Humic acid effect on catalase activity and the generation of reactive oxygen species in corn (Zea mays). Biosci. Biotechnol. Biochem. 75, 70-74. doi: $10.1271 /$ bbb. 100553

Corilo, Y. E. (2018). PetroOrg Software. Florida State University.

David, P. P., Nelson, P. V., and Sanders, D. C. (1994). A humic acid improves growth of tomato seedling in solution culture. J. Plant Nutr. 17, 173-184. doi: 10.1080/01904169409364717

De Hita, D., Fuentes, M., Zamarreño, A. M., Ruiz, Y., and Garcia-Mina, J. M. (2020). Culturable bacterial endophytes from sedimentary humic acid-treated plants. Front. Plant Sci. 11:837. doi: 10.3389/fpls.2020.00837

Fedoros, E. I., Orlov, A. A., Zherebker, A., Gubareva, E. A., Maydin, M. A., Konstantinov, A. I., et al. (2018). Novel water-soluble lignin derivative BP-Cx-1: identification of components and screening of potential targets in silico and in vitro. Oncotarget 9:18578. doi: 10.18632/oncotarget.24990

Fish, W. W., Perkins-Veazie, P., and Collins, J. K. (2002). A quantitative assay for lycopene that utilizes reduced volumes of organic solvents. J. Food Compos. Anal. 15, 309-317. doi: 10.1006/jfca.2002.1069
Foley, J. A., Ramankutty, N., Brauman, K. A., Cassidy, E. S., Gerber, J. S., Johnston, M., et al. (2011). Solutions for a cultivated planet. Nature 478, 337-342. doi: $10.1038 /$ nature 10452

García, A. C., Olaetxea, M., Santos, L. A., Mora, V., Baigorri, R., Fuentes, M., et al. (2016a). Involvement of hormone-and ROS-signaling pathways in the beneficial action of humic substances on plants growing under normal and stressing conditions. Biomed Res. Int. 2016:3747501. doi: 10.1155/2016/3747501

García, A. C., Santos, L. A., de Souza, L. G. A., Tavares, O. C. H., Zonta, E., Gomes, E. T. M., et al. (2016b). Vermicompost humic acids modulate the accumulation and metabolism of ROS in rice plants. J. Plant Physiol. 192, 56-63. doi: 10.1016/j.jplph.2016.01.008

García, A. C., Santos, L. A., Izquierdo, F. G., Sperandio, M. V. L., Castro, R. N., and Berbara, R. L. L. (2012). Vermicompost humic acids as an ecological pathway to protect rice plant against oxidative stress. Ecol. Eng. 47, 203-208. doi: 10.1016/j.ecoleng.2012.06.011

Garcia-Mina, J. M., Antolin, M. C., and Sanchez-Diaz, M. (2004). Metalhumic complexes and plant micronutrient uptake: a study based on different plant species cultivated in diverse soil types. Plant Soil 258, 57-68. doi: 10.1023/B:PLSO.0000016509.56780.40

Gniazdowska, A., Krasuska, U., Andrzejczak, O., and Soltys, D. (2015). "Allelopathic compounds as oxidative stress agents: YES or NO," in Reactive Oxygen and Nitrogen Species Signaling and Communication in Plants, eds. K. Gupta, and A. Igamberdiev (Cham: Springer), 155-176.

Grace, S. (2005). "Phenolics as antioxidants," in Antioxidants and Reactive Oxygen Species in Plant, ed N. Smirnoff (Wiley press), 141-168.

Gray, M. R., Tykwinski, R. R., Stryker, J. M., and Tan, X. (2011). Supramolecular assembly model for aggregation of petroleum asphaltenes. Energy Fuels 25, 3125-3134. doi: 10.1021/ef200654p

Hadacek, F., Bachmann, G., Engelmeier, D., and Chobot, V. (2011). Hormesis and a chemical raison d'être for secondary plant metabolites. Dose Response 9, 79-116. doi: 10.2203/dose-response.09-028.Hadacek

Hayes, M. H., and Swift, R. S. (2020). Vindication of humic substances as a key component of organic matter in soil and water. Adv. Agron. 163:1. doi: 10.1016/bs.agron.2020.05.001

Henderson, 1,. M., Thomas, S., Banting, G., and Chappell, J. B. (1997). The arachidonate-activatable, NADPH oxidase-associated $\mathrm{H}+$ channel is contained within the multi-membrane-spanning N-terminal region of gp91-phox. Biochem. J. 325, 701-705. doi: 10.1042/bj3250701

Hockaday, W. C., Purcell, J. M., Marshall, A. G., Baldock, J. A., and Hatcher, P. G. (2009). Electrospray and photoionization mass spectrometry for the characterization of organic matter in natural waters: a qualitative assessment. Limnol. Oceanogr. Methods 7, 81-95. doi: 10.4319/lom.2009.7.81

Jannin, L., Arkoun, M., Ourry, A., Laîné, P., Goux, D., Garnica, M., et al. (2012). Microarray analysis of humic acid effects on Brassica napus growth: involvement of N, C and S metabolisms. Plant Soil 359, 297-319. doi: 10.1007/s11104-012-1191-x

Jindo, K., Soares, T. S., Peres, L. E. P., Azevedo, I. G., Aguiar, N. O., Mazzei, P., et al. (2016). Phosphorus speciation and high-affinity transporters are influenced by humic substances. J. Plant Nutr. Soil Sci. 179, 206-214. doi: $10.1002 /$ jpln. 201500228

Kaiser, N. K., Savory, J. J., and Hendrickson, C. L. (2014). Controlled ion ejection from an external trap for extended $\mathrm{m} / \mathrm{z}$ range in FT-ICR mass spectrometry. J. Am. Soc. Mass Spectrom. 25, 943-949. doi: 10.1007/s13361-014-0871-6

Kaya, C., Senbayram, M., Akram, N. A., Ashraf, M., Alyemeni, M. N., and Ahmad, P. (2020). Sulfur-enriched leonardite and humic acid soil amendments enhance tolerance to drought and phosphorus deficiency stress in maize (Zea mays L.). Sci. Rep. 10, 1-13. doi: 10.1038/s41598-020-62669-6

Kelleher, B. P., and Simpson, A. J. (2006). Humic substances in soils: are they really chemically distinct? Environ. Sci. Technol. 40, 4605-4611. doi: $10.1021 /$ es0608085

Khillari, S. (2020). Biostimulant Market Analysis. Recent Industry Trends Report 2026.

Kleber, M., and Lehmann, J. (2019). Humic substances extracted by alkali are invalid proxies for the dynamics and functions of organic matter in terrestrial and aquatic ecosystems. J. Environ. Qual. 48, 207-216. doi: $10.2134 /$ jeq2019.01.0036

Koch, B. P., Witt, M., Engbrodt, R., Dittmar, T., and Kattner, G. (2005). Molecular formulae of marine and terrigenous dissolved organic matter 
detected by electrospray ionization Fourier transform ion cyclotron resonance mass spectrometry. Geochim. Cosmochim. Acta 69, 3299-3308. doi: 10.1016/j.gca.2005.02.027

Koleška, I., Hasanagić, D., Todorović, V., Murtić, S., Klokić, I., Paradiković, N., et al. (2017). Biostimulant prevents yield loss and reduces oxidative damage in tomato plants grown on reduced NPK nutrition. J. Plant Interact. 12, 209-218. doi: 10.1080/17429145.2017.1319503

Kramer, R. W., Kujawinski, E. B., and Hatcher, P. G. (2004). Identification of black carbon derived structures in a volcanic ash soil humic acid by Fourier transform ion cyclotron resonance mass spectrometry. Environ. Sci. Technol. 38, 3387-3395. doi: 10.1021/es030124m

Kruk, J., Szymańska, R., Nowicka, B., and Dłuzewska, J. (2016). Function of isoprenoid quinones and chromanols during oxidative stress in plants. New Biotechnol. 33, 636-643. doi: 10.1016/j.nbt.2016.02.010

Kujawinski, E. B. (2002). Electrospray ionization Fourier transform ion cyclotron resonance mass spectrometry (ESI FT-ICR MS): characterization of complex environmental mixtures. Environ. Forensics 3, 207-216. doi: $10.1080 / 713848382$

Kujawinski, E. B., Longnecker, K., Blough, N. V., Del Vecchio, R., Finlay, L., Kitner, J. B., et al. (2009). Identification of possible source markers in marine dissolved organic matter using ultrahigh resolution mass spectrometry. Geochim. Cosmochim. Acta 73, 4384-4399. doi: 10.1016/j.gca.2009.04.033

Kurutas, E. B. (2015). The importance of antioxidants which play the role in cellular response against oxidative/nitrosative stress: current state. Nutr. J. 15, 1-22. doi: $10.1186 / \mathrm{s} 12937-016-0186-5$

Lamar, R. T. (2010). "Possible role for electron shuttling capacity in elicitation of pb activity of humic substances on plant growth enhancement," in The Chemical Biology of Plant Biostimulants, eds D. Geelen, L. Xu, and C. V. Stevens (Wiley Press), 97-121.

Lamar, R. T., Olk, D. C., Mayhew, L., and Bloom, P. R. (2014). A new standardized method for quantification of humic and fulvic acids in humic ores and commercial products. J. AOAC Int. 97, 721-730. doi: 10.5740/jaoacint.13-393

Lv, J., Han, R., Huang, Z., Luo, L., Cao, D., and Zhang, S. (2018). Relationship between molecular components and reducing capacities of humic substances. ACS Earth Space Chem. 2, 330-339. doi: 10.1021/acsearthspacechem.7b00155

Lv, J., Zhang, S., Wang, S., Luo, L., Cao, D., and Christie, P. (2016). Molecularscale investigation with ESI-FT-ICR-MS on fractionation of dissolved organic matter induced by adsorption on iron oxyhydroxides. Environ. Sci. Technol. 50, 2328-2336. doi: 10.1021/acs.est.5b04996

Maji, D., Misra, P., Singh, S., and Kalra, A. (2017). Humic acid rich vermicompost promotes plant growth by improving microbial community structure of soil as well as root nodulation and mycorrhizal colonization in the roots of Pisum sativum. Appl. Soil Ecol. 110, 97-108. doi: 10.1016/j.apsoil.2016.10.008

Martinez-Balmori, D., Spaccini, R., Aguiar, N. O., Novotny, E. H., Olivares, F. L., and Canellas, L. P. (2014). Molecular characteristics of humic acids isolated from vermicomposts and their relationship to bioactivity. J. Agric. Food Chem. 62, 11412-11419. doi: 10.1021/jf504629c

McKenna, A. M., Chacón-Patiño, M. L., Weisbrod, C. R., Blakney, G. T., and Rodgers, R. P. (2019). Molecular-level characterization of asphaltenes isolated from distillation cuts. Energy Fuels 33, 2018-2029. doi: 10.1021/acs.energyfuels.8b04219

McKenna, A. M., Marshall, A. G., and Rodgers, R. P. (2013). Heavy petroleum composition. 4. Asphaltene compositional space. Energy Fuels 27, 1257-1267. doi: $10.1021 / \mathrm{ef} 301747 \mathrm{~d}$

Mehrasbi, M. R., Fathi, P., Hosseini, M. J., and Sadeghi, G. (2018). Investigation the effects of humic acid on growth rate and active oxygen radicals (ROS) production in Chlorella Vulgaris algae. J. Health 9, 423-431. doi: $10.29252 /$ j.health.9.4.423

Meticulous Market Research. (2019). Biostimulants Market by Active Ingredient (Acid Based, Extracts based), Application (Foliar Spray, Soil Treatment, Seed Treatment), Formulation (Liquid, Dry), and Crop Type (Row Crops, Fruits and Vegetables) - Global Forecast to 2025. Available online at: https:// www.meticulousresearch.com/product/biostimulants-market-5057 (accessed January 2021).

Monda, H., Cozzolino, V., Vinci, G., Drosos, M., Savy, D., and Piccolo, A. (2018). Molecular composition of the Humeome extracted from different green composts and their biostimulation on early growth of maize. Plant Soil 429, 407-424. doi: 10.1007/s11104-018-3642-5
Namikoshi, M. (2006). "Biologically active natural products from marine fungi," in Biomaterials from Aquatic and Terrestrial Organism, eds. M. Fingerman, and R. Nagabhushanam (Enfield, NH: Science Publishers), 285-359.

Nardi, S., Concheri, G., Dell'Agnola, G., and Scrimin, P. (1991). Nitrate uptake and ATPase activity in oat seedlings in the presence of two humic fractions. Soil Biol. Biochem. 23, 833-836. doi: 10.1016/0038-0717(91)90094-Z

Nardi, S., Ertani, A., and Francioso, O. (2017). Soil-root cross-talking: the role of humic substances. J. Plant Nutr. Soil Sci. 180, 5-13. doi: 10.1002/jpln.2016 00348

Neumann, G., and Römheld, V. (2007). The release of root exudates as affected by the plant physiological status. Rhizosphere 2, 23-72. doi: $10.1201 / 9781420005585 . c h 2$

Nielsen, S. S. (eds.). (2017). "Vitamin C determination by indophenol method," in Food Analysis Laboratory Manual (Cham: Springer), 143-146.

Ohno, T., He, Z., Sleighter, R. L., Honeycutt, C. W., and Hatcher, P. G. (2010). Ultrahigh resolution mass spectrometry and indicator species analysis to identify marker components of soil-and plant biomass-derived organic matter fractions. Environ. Sci. Technol. 44, 8594-8600. doi: 10.1021/es10 $1089 \mathrm{t}$

Ohno, T., and Ohno, P. E. (2013). Influence of heteroatom preselection on the molecular formula assignment of soil organic matter components determined by ultrahigh resolution mass spectrometry. Anal. Bioanal. Chem. 405, 3299-3306. doi: 10.1007/s00216-0136734-3

Olaetxea, M., Mora, V., Baigorri, R., Zamarreño, A. M., and García-Mina, J. M. (2021). The Singular molecular conformation of humic acids in solution influences their ability to enhance root hydraulic conductivity and plant growth. Molecules 26:3. doi: 10.3390/molecules 26010003

Olk, D. C., Bloom, P. R., De Nobili, M., Chen, Y., McKnight, D. M., Wells, M. J. M., et al. (2019). Using humic fractions to understand natural organic matter processes in soil and water: Selected studies and applications. J. Environ. Qual. 48, 1633-1643. doi: 10.2134/jeq2019.03.0100

Orlov, A. A., Zherebker, A., Eletskaya, A. A., Chernikov, V. S., Kozlovskaya, L. I., Zhernov, Y. V., et al. (2019). Examination of molecular space and feasible structures of bioactive components of humic substances by FTICR MS data mining in ChEMBL database. Sci. Rep. 9, 1-12. doi: 10.1038/s41598-019-48000-y

Piccolo, A. (2001). The supramolecular structure of humic substances. Soil Sci. 166, 810-832. doi: 10.1097/00010694-200111000-00007

Piccolo, A., Spiteller, M., and Nebbioso, A. (2010). Effects of sample properties and mass spectroscopic parameters on electrospray ionization mass spectra of size-fractions from a soil humic acid. Anal. Bioanal. Chem. 397, 3071-3078. doi: 10.1007/s00216-010-3884-4

Pietsch, K., Saul, N., Chakrabarti, S., Stürzenbaum, S. R., Menzel, R., and Steinberg, C. E. (2011). Hormetins, antioxidants and prooxidants: defining quercetin, caffeic acid-and rosmarinic acid-mediated life extension in C. elegans. Biogerontology 12, 329-347. doi: 10.1007/s10522-011-9334-7

Pietta, P. G. (2000). Flavonoids as antioxidants. J. Nat. Prod. 63, 1035-1042. doi: $10.1021 / \mathrm{np} 9904509$

Pilanal, N., and Kaplan, M. (2003). Investigation of effects on nutrient uptake of humic acid applications of different forms to strawberry plant. J. Plant Nutr. 26, 835-843. doi: 10.1081/PLN-120018568

Pizzeghello, D., Schiavon, M., Francioso, O., Dalla Vecchia, F., Ertani, A., and Nardi, S. (2020). Bioactivity of size-fractionated and unfractionated humic substances from two forest soils and comparative effects on $\mathrm{N}$ and $\mathrm{S}$ metabolism, nutrition, and root anatomy of Allium sativum L. Front. Plant Sci. 11:1203. doi: $10.3389 /$ fpls.2020.01203

Puglisi, E., Fragoulis, G., Ricciuti, P., Cappa, F., Spaccini, R., Piccolo, A., et al. (2009). Effects of humic acid and its size-fractions on the bacterial community of soil rhizosphere under maize (Zea mays L.). Chemosphere 77, 829-837 doi: 10.1016/j.chemosphere.2009.07.077

Puglisi, E., Pascazio, S., Suciu, N., Cattani, I., Fait, G., Spaccini, R., et al. (2013). Rhizosphere microbial diversity as influenced by humic substance amendments and chemical composition of rhizodeposits. J. Geochem. Explor. 129, 82-94. doi: 10.1016/j.gexplo.2012.10.006

Ramírez, S., L. F., Muro, E., J., and Sánchez, G., P. (2009). Potassium affects the lycopene and $\beta$-carotene concentration in greenhouse tomato. Acta Hortic. 821, 223-227. doi: 10.17660/ActaHortic.2009.821.25 
Remucal, C. K., Cory, R. M., Sander, M., and McNeill, K. (2012). Low molecular weight components in an aquatic humic substance as characterized by membrane dialysis and orbitrap mass spectrometry. Environ. Sci. Technol. 46, 9350-9359. doi: 10.1021/es302468q

Roomi, S., Masi, A., Conselvan, G. B., Trevisan, S., Quaggiotti, S., Pivato, M., et al. (2018). Protein profiling of arabidopsis roots treated with humic substances: insights into the metabolic and interactome networks. Front. Plant Sci. 9:1812. doi: 10.3389/fpls.2018.01812

Rose, M. T., Patti, A. F., Little, K. R., Brown, A. L., Jackson, W. R., and Cavagnaro, T. R. (2014). A meta-analysis and review of plantgrowth response to humic substances: practical implications for agriculture. Adv. Agron. 124, 37-89. doi: 10.1016/B978-0-12-800138-7. 00002-4

Rostad, C. E., and Leenheer, J. A. (2004). Factors that affect molecular weight distribution of Suwannee river fulvic acid as determined by electrospray ionization/mass spectrometry. Anal. Chim. Acta 523, 269-278. doi: 10.1016/j.aca.2004.06.065

Rouphael, Y., and Colla, G. (2018). Synergistic biostimulatory action: designing the next generation of plant biostimulants for sustainable agriculture. Front. Plant Sci. 9:1655. doi: 10.3389/fpls.2018.01655

Savory, J. J., Kaiser, N. K., McKenna, A. M., Xian, F., Blakney, G. T., Rodgers, R. P., et al. (2011). Parts-per-billion Fourier transform ion cyclotron resonance mass measurement accuracy with a "walking" calibration equation. Anal. Chem. 83, 1732-1736. doi: $10.1021 /$ ac102943z

Schachtman, D. P., and Shin, R. (2007). Nutrient sensing and signaling: NPKS. Annu. Rev. Plant Biol. 58, 47-69. doi: 10.1146/annurev.arplant.58.032806.103750

Senthamarai, R., Umadevi, G., and Ganesh, K. J. (2003). Antimicrobial activity of root extracts of Dalbergia spinosa Roxb. Anc. Sci. Life 22:84-87.

Sleighter, R. L., and Hatcher, P. G. (2007). The application of electrospray ionization coupled to ultrahigh resolution mass spectrometry for the molecular characterization of natural organic matter. J. Mass Spectrom. 42, 559-574. doi: $10.1002 /$ jms.1221

Spaccini, R., and Piccolo, A. (2007). Molecular characterization of compost at increasing stages of maturity. 2. Thermochemolysis- GC-MS and ${ }^{13} \mathrm{C}-\mathrm{CPMAS}-$ NMR spectroscopy. J. Agric. Food Chem. 55, 2303-2311. doi: 10.1021/jf062 5407

Stenson, A. C., Landing, W. M., Marshall, A. G., and Cooper, W. T. (2002). Ionization and fragmentation of humic substances in electrospray ionization Fourier transform-ion cyclotron resonance mass spectrometry. Anal. Chem. 74, 4397-4409. doi: 10.1021/ac020019f

Stevenson, F. J. (1994). Humus Chemistry: Genesis, Composition, Reactions. New York, NY: John Wiley and Sons.

Sturdy, M., Krunic, A., Cho, S., Franzblau, S., and Orjala, J. (2010). Eucapsitrione, an anti-Mycobacterium tuberculosis anthraquinone derivative from the cultured freshwater cyanobacterium Eucapsis sp. J. Nat. Prod. 73, 1441-1443. doi: $10.1021 / \mathrm{np} 100299 \mathrm{v}$

Sutton, R., and Sposito, G. (2005). Molecular structure in soil humic substances: the new view. Environ. Sci. Technol. 39, 9009-9015. doi: 10.1021/es05 $0778 \mathrm{q}$

Swift, R. S. (1996). "Organic matter characterization," in Methods of Soil Analysis Part 3-Chemical Methods, eds. A. Klute, A. L. Ulery, and R. Drees, (Madison, WI: SSSA Press), 1011-1069.

Tavares, O. C. H., Santos, L. A., de Araújo, O. J. L., Bucher, C. P. C., García, A. C., Arruda, L. N., et al. (2019). Humic acid as a biotechnological alternative to increase $\mathrm{N}_{-} \mathrm{NO}_{3}$-or $\mathrm{N}-\mathrm{NH}_{4}^{+}$uptake in rice plants. Biocatal. Agric. Biotechnol. 20:101226. doi: 10.1016/j.bcab.2019.10 1226

Tavares, O. C. H., Santos, L. A., Ferreira, L. M., Sperandio, M. V. L., da Rocha, J. G., García, A. C., et al. (2017). Humic acid differentially improves nitrate kinetics under low-and high-affinity systems and alters the expression of plasma membrane H+-ATPases and nitrate transporters in rice. Ann. Appl. Biol. 170, 89-103. doi: 10.1111/aab.12317

Tomasi, N., Mimmo, T., Terzano, R., Alfeld, M., Janssens, K., Zanin, L., et al. (2014). Nutrient accumulation in leaves of Fe-deficient cucumber plants treated with natural Fe complexes. Biol. Fertil. Soils 50, 973-982. doi: 10.1007/s00374-014-0919-6

Trejo-Téllez, L. I., Estrada-Ortiz, E., Gómez-Merino, F. C., Becker, C., Krumbein, A., and Schwarz, D. (2019). Flavonoid, nitrate and glucosinolate concentrations in Brassica species are differentially affected by photosynthetically active radiation, phosphate and phosphite. Front. Plant Sci. 10:371. doi: $10.3389 /$ fpls.2019.00371

Treml, J., and Šmejkal, K. (2016). Flavonoids as potent scavengers of hydroxyl radicals. Comp. Rev. Food Sci. Food Saf. 15, 720-738. doi: 10.1111/1541-4337.12204

Van Krevelen, D. W. (1950). Graphical-statistical method for the study of structure and reaction processes of coal. Fuel 29, 269-284.

Varanini, Z., Pinton, R., De Biasi, M. G., Astolfi, S., and Maggioni, A. (1993). Low molecular weight humic substances stimulate H+ATPase activity of plasma membrane vesicles isolated from oat (Avena sativa L.) roots. Plant Soil. 153, 61-69. doi: 10.1007/BF00 010544

Vargas-Hernandez, M., Macias-Bobadilla, I., Guevara-Gonzalez, R. G., Romero-Gomez, S. D. J., Rico-Garcia, E., Ocampo-Velazquez, R. V., et al. (2017). Plant hormesis management with biostimulants of biotic origin in agriculture. Front. Plant Sci. 8:1762. doi: 10.3389/fpls.2017. 01762

Vitousek, P. M., Naylor, R., Crews, T., David, M. B., Drinkwater, L. E., Holland, E., et al. (2009). Nutrient imbalances in agricultural development. Science 324, 1519-1520. doi: 10.1126/science.1170261

Vredenberg, W. (2011). Kinetic analyses and mathematical modeling of primary photochemical and photoelectrochemical processes in plant photosystems. Biosystems 103, 138-151. doi: 10.1016/j.biosystems.2010. 10.016

Weber, J., Chen, Y., Jamroz, E., and Miano, T. (2018). Preface: humic substances in the environment. J. Soils Sediments 18, 2665-2667. doi: 10.1007/s11368-018-2052-x

Xian, F., Corilo, Y. E., Hendrickson, C. L., and Marshall, A. G. (2012). Baseline correction of absorption-mode Fourier transform ion cyclotron resonance mass spectra. Int. J. Mass Spectrom. 325, 67-72. doi: 10.1016/j.ijms.2012. 06.007

Xian, F., Hendrickson, C. L., Blakney, G. T., Beu, S. C., and Marshall, A. G. (2010). Automated broadband phase correction of Fourier transform ion cyclotron resonance mass spectra. Anal. Chem. 82, 8807-8812. doi: 10.1021/ac10 $1091 \mathrm{w}$

Yang, Z., Kappler, A., and Jiang, J. (2016). Reducing capacities and distribution of redox-active functional groups in low molecular weight fractions of humic acids. Environ. Sci. Technol. 50, 12105-12113. doi: 10.1021/acs.est.6b 02645

Zandonadi, D. B., Canellas, L. P., and Façanha, A. R. (2007). Indolacetic and humic acids induce lateral root development through a concerted plasmalemma and tonoplast $\mathrm{H}+$ pumps activation. Planta 225, 1583-1595. doi: 10.1007/s00425-006-0454-2

Zandonadi, D. B., Santos, M. P., Dobbss, L. B., Olivares, F. L., Canellas, L. P., Binzel, M. L., et al. (2010). Nitric oxide mediates humic acids-induced root development and plasma membrane $\mathrm{H}+-$ ATPase activation. Planta 231, 1025-1036. doi: 10.1007/s00425-0101106-0

Zanin, L., Tomasi, N., Zamboni, A., Sega, D., Varanini, Z., and Pinton, R. (2018). Water-extractable humic substances speed up transcriptional response of maize roots to nitrate. Environ. Exp. Bot. 147, 167-178. doi: 10.1016/j.envexpbot.2017. 12.014

Zdravković, J., Marković, Z., Zdravković, M., Damjanović, M., and Pavlović, N. (2004). "Relation of mineral nutrition and content of lycopene and $\beta$-carotene in tomato (Lycopersicon esculentum Mill.) fruits. Acta Hortic. 729, 177-181. doi: 10.17660/ActaHortic.2007.729.27

Zhang, N., Zhang, D. D., Ji, H. D., Yu, X. W., Zhang, Z. C., Yang, S. M., et al. (2018). Redox structures of humic acids derived from different sediments and their effects on microbial reduction reactions. Front. Microbiol. 9:1225. doi: $10.3389 /$ fmicb. 2018.01225 
Zherebker, A., Podgorski, D. C., Kholodov, V. A., Orlov, A. A., Yaroslavtseva, N. V., Kharybin, O., et al. (2019). The molecular composition of humic substances isolated from yedoma permafrost and alas cores in the eastern Siberian Arctic as measured by ultrahigh resolution mass spectrometry. J. Geophys. Res. Biogeosci. 124, 2432-2445. doi: 10.1029/2018JG 004743

Zhernov, Y. V., Konstantinov, A. I., Zherebker, A., Nikolaev, E., Orlov, A., Savinykh, M. I., et al. (2020). Antiviral activity of natural humic substances and shilajit materials against HIV-1: Relation to structure. Environ. Res. 193:110312. doi: 10.1016/j.envres.2020.110312

Zykova, M. V., Schepetkin, I. A., Belousov, M. V., Krivoshchekov, S. V., Logvinova, L. A., Bratishko, K. A., et al. (2018). Physicochemical characterization and antioxidant activity of humic acids isolated from peat of various origins. Molecules 23:753. doi: 10.3390/molecules 23040753
Conflict of Interest: HM, RL, and RF were employed by the company Bio Huma Netics, Inc.

The remaining author declares that the research was conducted in the absence of any commercial or financial relationships that could be construed as a potential conflict of interest.

Copyright $\odot 2021$ Monda, McKenna, Fountain and Lamar. This is an open-access article distributed under the terms of the Creative Commons Attribution License (CC $B Y)$. The use, distribution or reproduction in other forums is permitted, provided the original author(s) and the copyright owner(s) are credited and that the original publication in this journal is cited, in accordance with accepted academic practice. No use, distribution or reproduction is permitted which does not comply with these terms. 